\title{
Immunometabolism: Another Road to Sepsis and Its Therapeutic Targeting
}

\author{
Vijay Kumar ${ }^{1,2,3}$
}

\begin{abstract}
Sepsis is a major health problem all over the world. Despite its existence since the time of Hippocrates (470 BC), sepsis is still a serious medical problem for physicians working in both pediatric and adult intensive care units. The most current US FDA-approved drug called recombinant human activated protein $C$ or Drotrecogin- $\alpha$ is also failed in clinical trials and showed similar effects as placebo. The epidemiological data and studies have indicated sepsis as a major socioeconomic burden all over the world. Advances in immunology and genomic medicine have established different immunological mechanisms as major regulators of the pathogenesis of the sepsis. These immunological mechanisms come into action upon activation of several components of the immune system including innate and adaptive immunity. The activation of these immune cells in response to the pathogens or pathogen-associated molecular patterns (PAMPs) responsible for the onset of sepsis is regulated by the metabolic stage of the immune cells called immunometabolism. An alternation in the immunometabolism is responsible for the generation of dysregulated immune response during sepsis and plays a very important role in the process. Thus, it becomes vital to understand the immunometabolic reprograming during sepsis to design future target-based therapeutics depending on the severity. The current review is designed to highlight the importance of immune response and associated immunometabolism during sepsis and its targeting as a future therapeutic approach.
\end{abstract}

KEY WORDS: sepsis; immunometabolism; innate immunity; neutrophils; MDSCs; pathogens.

\section{INTRODUCTION}

Sepsis is a major healthcare problem for physicians working in intensive care units (ICUs) along with the medical research scientists involved in sepsis research. It is characterized as a disease with a constellation of symptoms originating

\footnotetext{
${ }^{1}$ Children's Health Queensland Clinical Unit, Department of Paediatrics and Child Care, School of Clinical Medicine, Mater Research, Faculty of Medicine, University of Queensland, ST Lucia, Brisbane, QLD 4078, Australia

${ }^{2}$ School of Biomedical Sciences, Faculty of Medicine, University of Queensland, ST Lucia, Brisbane, QLD 4078, Australia

${ }^{3}$ To whom correspondence should be addressed at School of Biomedical Sciences, Faculty of Medicine, University of Queensland, ST Lucia, Brisbane, QLD 4078, Australia. E-mail: vij_tox@yahoo.com
}

from the dysregulated immune response against an invading pathogen (i.e., bacteria (both gram negative and gram positive), viruses, fungi as well as a parasite) responsible for the systemic infection and induction of systemic inflammation. The pathophysiological symptoms involved are characterized by the presence of hyper/hypothermia, leukocytosis/leukopenia, hypertension, hypotension due to decreased resistance causing induction of septic shock, disseminated intravascular coagulation (DISC), multi-organ damage/failure (severe sepsis), and ultimate death of the patient. According to the recommendations by the third international consensus definitions for sepsis and septic shock (Sepsis-3), sepsis should be defined as a life-threatening condition of organ dysfunction caused by a dysregulated immune response to infection [1]. 
For the clinical purpose, organ dysfunction can be shown by an increase in the Sequential [Sepsis-related] Organ Failure Assessment (SOFA) score of 2 points or more that is associated with an in-hospital mortality greater than $10 \%$ [1]. Thus, as per definition, sepsis and severe sepsis can thus be used interchangeably sometimes to illustrate the constellation of symptoms caused by certain infections along with distant organ injury/dysfunction [2]. As per sepsis-3 guidelines, septic shock is defined as a subset of sepsis with particularly profound circulatory, cellular, and metabolic abnormalities cause a greater risk of mortality than with sepsis/severe sepsis alone [1]. The patients with septic shock can be clinically identified by a vasopressor requirement to maintain a mean arterial pressure of $65 \mathrm{mmHg}$ or greater and serum lactate level greater than $2 \mathrm{mmol} / \mathrm{L}(>18 \mathrm{mg} / \mathrm{dL})$ in the absence of hypovolemia $[1,3]$.

With the discoveries and advancements in antibiotic therapies, ventilator management of respiratory difficulties observed in patients with sepsis/acute pneumonia, blood glucose maintenance, and advanced resuscitative strategies, an improved outcome in sepsis-associated mortality is reported [4-6]. But still, the mortality associated with severe sepsis and septic shock approaches to $50 \%$ in some countries whereas in other countries it lies between 20 and $30 \%$ [7]. Still with the advancement in the management of sepsis, its annual incidence is very high in high-income/ developed countries and it accounts for 5.3 million deaths annually $[8,9]$. Additionally, the emergence of pathogens with antibiotic resistance has created another challenge for intensivist dealing with sepsis patients. For example, antimicrobial resistance has become a great challenge to manage both adult and neonatal sepsis all over the world [1012]. Thus, alternative approaches targeting sepsis along with a combination of appropriate antibiotics at appropriate time are highly desired [13]. One of the alternative approaches includes targeting host immune cells to clear the infection responsible for the development of uncontrolled infection and inflammatory damage observed in sepsis/ severe sepsis [14]. Thus, to target host immune system effectively during sepsis, a better understanding of immunopathogenesis is essential as described in the following section. Immunometabolism controlling the development and function of immune cells during homeostasis and different diseases including autoimmune diseases, cancers, and infections may provide an alternative approach to target immune cells that get dysregulated in terms of their function and survival during sepsis [15-19]. Thus, the major emphasis of the review is to highlight the importance of immune cells including neutrophils, myeloid-derived suppressor cells (MDSCs), macrophages and $\mathrm{T}$ cells in the pathogenesis of sepsis, alteration in their immunometabolic stage, and its therapeutic targeting.

\section{IMMUNE RESPONSE DURING SEPSIS}

The immune system plays a major role in hostpathogen interaction; therefore, an establishment or clearance of the infection depends on the immunological status of the host [20-22]. However, the immune system is not fully developed in neonates and therefore fails to mount an effective immune response to clear the invading pathogen and causing the development of sepsis [23-25]. Whereas proper functioning of the immune system (i.e., the balance between anti-inflammatory or pro-inflammatory immune response) also gets compromised in older population due to the process called immunoaging [26-29]. Thus, the failure of the immune system to clear the pathogen and an induction of dysregulated immune response in both age groups predisposes them to develop sepsis and associated mortality.

The role of immune system in the pathogenesis of sepsis in detail is described elsewhere [30-34]. Thus, I will briefly explain the role of immune system here in the pathogenesis of sepsis. An initial encounter of the host with a specific pathogen leads to the phenomenon of host-pathogen interaction. This may either lead to the clearance of the infection or may provide an opportunity to form an ecological niche favoring survival, growth, and division of the bacteria. During this stage, the pathogen is taken care mainly by the innate immune system comprising of innate immune cells and its humoral components including the complement system, cytokines, chemokines etc. [30, 35-37]. Additionally, the endothelial cells (ECs) are also considered as innate immune cells and secrete proinflammatory cytokines upon interaction with different PAMPs via different PRRs [38-40]. Furthermore, mice expressing exclusively TLR4 on ECs efficiently clear systemic bacterial infection during lethal sepsis [41]. However, in actual human cases of sepsis, a profound damage to the endothelial lining or ECs is observed causing a defective vasoregulation, inflammation, induction of oxidative and nitrosative stresses, induction of septic shock, and multi-organ dysfunction syndrome (MODS) [42-47]. Thus, the failure of the innate immune system to clear the pathogen at this stages causes its profound activation leading to the induction of overwhelming release of proinflammatory cytokines (i.e., IL- $1 \alpha$, IL-1 $\beta$, TNF- $\alpha$, IL-6, IL-8, IL-12, IL-17, IL-18, granulocyte-monocyte colony stimulating factor (GM-CSF), interferon (IFN)- $\gamma$, 
macrophage migration factor (MIF) etc.) causing the induction of a phenomenon called "cytokine storm" [48-50]. In addition to pro-inflammatory cytokines, antiinflammatory cytokines (i.e., IL-10, transforming growth factor- $\beta$ (TGF- $\beta$ ), IL-30, and IL-37 etc.) are also generated and released during sepsis and their persistent overproduction exert great impact on sepsis pathogenesis and its outcome [51-54].

\section{FAILURE OF EARLIER IMMUNE-BASED THER- APEUTICS AND NEED FOR AN ALTERNATIVE APPROACH TO TARGET SEPSIS}

Various strategies were applied earlier to target sepsis via using immune-based therapies as mentioned [55]. For example, intravenous immunoglobulins (ivIGs) had been used in Streptococcal toxic shock syndrome (STSS) but with little success and is not recommended for these patients nowadays [56-58]. Additionally, inhibition of IL-1, IL-6, and TNF- $\alpha$ did not show a significant impact on sepsis-associated mortality and failed in their clinical trials [59]. Furthermore, targeting of a pattern-recognition receptor (PRR) called toll-like receptor-4 (TLR4) involved in the recognition of lipopolysaccharide (LPS) of gram-negative bacteria with eritoran tetrasodium (E5564) also failed in clinical trials $[59,60]$. The most recently developed drug (recombinant human activated protein $\mathrm{C}$ or Drotrecogin- $\alpha$, first USA FDA-approved drug for sepsis) designed to prescribe during sepsis-associated disseminated intravascular coagulation (DISC) also did not show any significant benefit to sepsis patients in 28 or 90 days mortality trial in comparison to placebo [61, 62]. These failures in clinical trials have left us without any direct therapeutic against sepsis since its description by Hippocrates in 430 BC [63, 64]. Further studies in this direction also indicate that immune status of the patient exerts a major impact on the course of septic shock and their susceptibility to getting infected with a hospital or ICU-acquired infections [65, 66]. Thus, the complexity of sepsis pathogenesis also involves the immune status of the person infected in terms of the comorbidity associated sepsis and different endpoints in sepsis/septic shock associated clinical findings $[65,66]$. Thus, an effective management of sepsis via modulating immune system requires a very specific and direct approach specifically depending on the immune cell's physiological status. This can be achieved by targeting metabolic status of immune cells or immune cell metabolism called immunometabolism.

\section{IMMUNOMETABOLISM AND ITS REPROGRAMMING DURING SEPSIS}

Immunometabolism is an interdisciplinary field that originates from the combination of classical immunology and metabolism that utilizes the experimental preferences and archetypes of both the branches of basic medical science [67]. This is further classified into two main streams: (a) Cellular immunometabolism involves the study of reprogramming of immune cell metabolism under different (i.e., homeostasis or pathological conditions including inflammation, infection, or cancer etc.) situations that determines their destiny [68, 69] and (b) Tissue immunometabolism that mainly deals with the impact of the immune cells on tissue and systemic metabolism that favors the required transformation of an individual or an organism to environmental changes [67]. Immunometabolism exerts its regulatory role on the immune system and associated diseases including infections, cancer, and autoimmunity $[17,70,71]$. This development in the field has also fascinated metabolomics towards immunology and sepsis research $[72,73]$. This current review is highlighting the importance of immunometabolism in terms of sepsis immunopathogenesis and its targeting as a future therapeutic approach.

\section{Immunometabolism and the Pathogenesis of Sepsis}

Sepsis is a disease of aberrant and dysregulated immune response to certain infections (i.e., Streptococcal infections, Staphylococcal infections and/or infection caused by Pseudomonas aeruginosa, Klebsiella pneumoniae etc.) that are more frequent in both neonates and older population (i.e., $\geq 60$ years of age) [23, 74]. Most of the immunologists, microbiologists, and ICU specialists remember metabolism as a course taught with physiology and biochemistry classes during their undergraduate studies called protein/amino acid metabolism, carbohydrate metabolism (glycolysis, gluconeogenesis, lactate metabolism, oxidative phosphorylation (OXPHOS), Krebs or tricarboxylic acid (TCA) cycle etc.) lipid metabolism comprising of lipid synthesis and its oxidation called betaoxidation of fatty acids (FAs). Still, the metabolism is mainly linked to metabolic diseases like obesity, diabetes mellitus or protein-energy malnutrition (PEM). However, an advancement in the field of immunology and infectious diseases has also implicated the metabolic changes in the functional state of immune cells during various inflammatory and infectious diseases [71, 75-79]. This advancement in the field of immunology led to the development of a 
branch of immunology called immunometabolism dealing with the study of the metabolism of immune cells during homeostasis and infectious and inflammatory diseases [70, 80]. For example, anorexia proves beneficial to host during bacterial (Listeria monocytogenes) sepsis and nutritional supplementation proves detrimental during with bacterial sepsis [81]. Whereas during viral infections including influenza and associated viral sepsis, food supplementation proves beneficial to the host and limiting the glucose intake increases the mortality [81]. Thus, this study indicates that individual's nutrient intake affects the immune cell function via impacting their metabolic stage during infections/ sepsis. Therefore, the activation, division, growth, proliferation, and effector function of immune cells and returning back to their homeostasis are linked and dependent on their metabolic status and the processes or stimuli impacting their metabolic processes. Hence, immunometabolism can be defined as metabolic process exhibited by immune cells in their various compartments during homeostasis or disease conditions that control all their homeostatic and effector functions.

Under the normal homeostatic condition, the immunologic response of immune cells required to maintain the homeostasis is effectively controlled via the process of immunometabolism [82]. For example, OXPHOS plays a major metabolic pathway to synthesize ATP molecules required as a source of energy for their growth and proliferation $[80,83]$. The process of OXPHOS depends on glycolysis, Krebs cycle, fatty acid synthesis (FAS) and its oxidation along with the process of glutaminolysis $[80,83$, 84]. Thus, under normal conditions, OXPHOS plays a major role to maintain the metabolic energy requirements of the immune cells.

\section{Neutrophils and Changes in Their Immunometabolism During Sepsis}

Neutrophils are major circulating innate immune cells in addition to monocytes with potent phagocytic and intracellular killing activity due to the generation of highly reactive oxygen species (ROS) [85-89]. Microarray data has shown the upregulation of 2248 gene transcripts in neutrophils of the persons voluntarily challenged with intravenous lipopolysaccharide (LPS) or endotoxin [90]. These genes are mainly upregulated during inflammatory process (i.e., genes involved in TNF- $\alpha$, IL- $1 \alpha$, and IL- $1 \beta$ signaling) and are the negative regulators of apoptosis [90]. This upregulation of pro-inflammatory genes and antiapoptotic genes (i.e., Bcl-xL, Mcl-1, A1, and Bak) in neutrophils proves detrimental to the pathogens but also exerts bystander inflammatory action on various organs or tissues where these cells are infiltrated causing multi-organ dysfunction syndrome (MODS) (Fig. 1a) [91-94]. Thus, the suppression of neutrophil apoptosis during sepsis may prove detrimental to the host via increasing the apoptosis of other cells through increasing the dephosphorylation of epithelial cell caspase-8 [95].

An increased upregulation of PDL-1 (Programmed death ligand-1) is observed on neutrophils isolated from sepsis patients and its interaction with PD-1 (Programmed death receptor-1) expressed on lymphocytes can induce the death of the $\mathrm{CD}^{+}, \mathrm{CD}^{+}$or $\mathrm{CD} 4^{+} \mathrm{CD} 8^{+} \mathrm{T}$ cells (Fig. 1a) [96]. For example, this neutrophil PDL-1 upon engagement with PD-1 on the T cells can inhibit their stimulatory signaling event mediated by TCR signal transduction and CD28-co-stimulation even at very low levels of PD-1 [97, 98]. This interaction inhibits the cytokine production required for T cell survival and proliferation, promotes cell cycle arrest and decreases the transcription of the antiapoptotic factor Bcl- $\mathrm{X}_{\mathrm{L}}$ [99]. The event is regulated by the termination of ZAP70 and PI3K phosphorylation through the recruitment of SHP1 (Src homology region 2 domain-containing phosphatase-1) and SHP2 (Src homology region 2 domain-containing phosphatase-2) phosphatases to the tyrosine phosphorylated ITIM (Immunoreceptor tyrosine-based inhibitory motif) and ITSM (Immunoreceptor tyrosine-based switch motif) motifs of PD1 [100-102]. This PDL-1 and PD-1 interaction indirectly regulates the expression and activities of CK2 (Casein kinase 2) and cyclin-dependent kinases (CDKs), thus blocking the phosphorylation of PTEN (Phosphatase and tensin homolog) and inhibiting the PI3K/AKT signaling $[98,103]$. Furthermore, PDL-1-PD-1 interaction also frequently reprograms immunometabolic stage of $\mathrm{T}$ cells from an effector to a long-lived memory-like phenotype indicated by an inhibition of glycolysis and amino acid metabolism but the activation of fatty acid $\beta$-oxidation (FAO) via increasing the expression of CPT1A (Carnitine Palmitoyltransferase 1A), and inducing lipolysis as indicated by expression of lipase, ATGL (Adipose triglyceride lipase), lipolysis markers and the release of FAs [104]. The change in the immunometabolic stage of T cells upon PDL1 and PD-1 interaction is true for chronic infections and cancers but needs to be explored during sepsis. However, according to the current scenario, sustained PD1 stimulation is responsible for $\mathrm{T}$ cell exhaustion and their death. Further studies regarding PD1 signaling in T cell differentiation and survival have a great potential to expand the role of PD1-PDL-1 signaling in T cell-based immunosuppression during sepsis. Furthermore, the neutrophils 


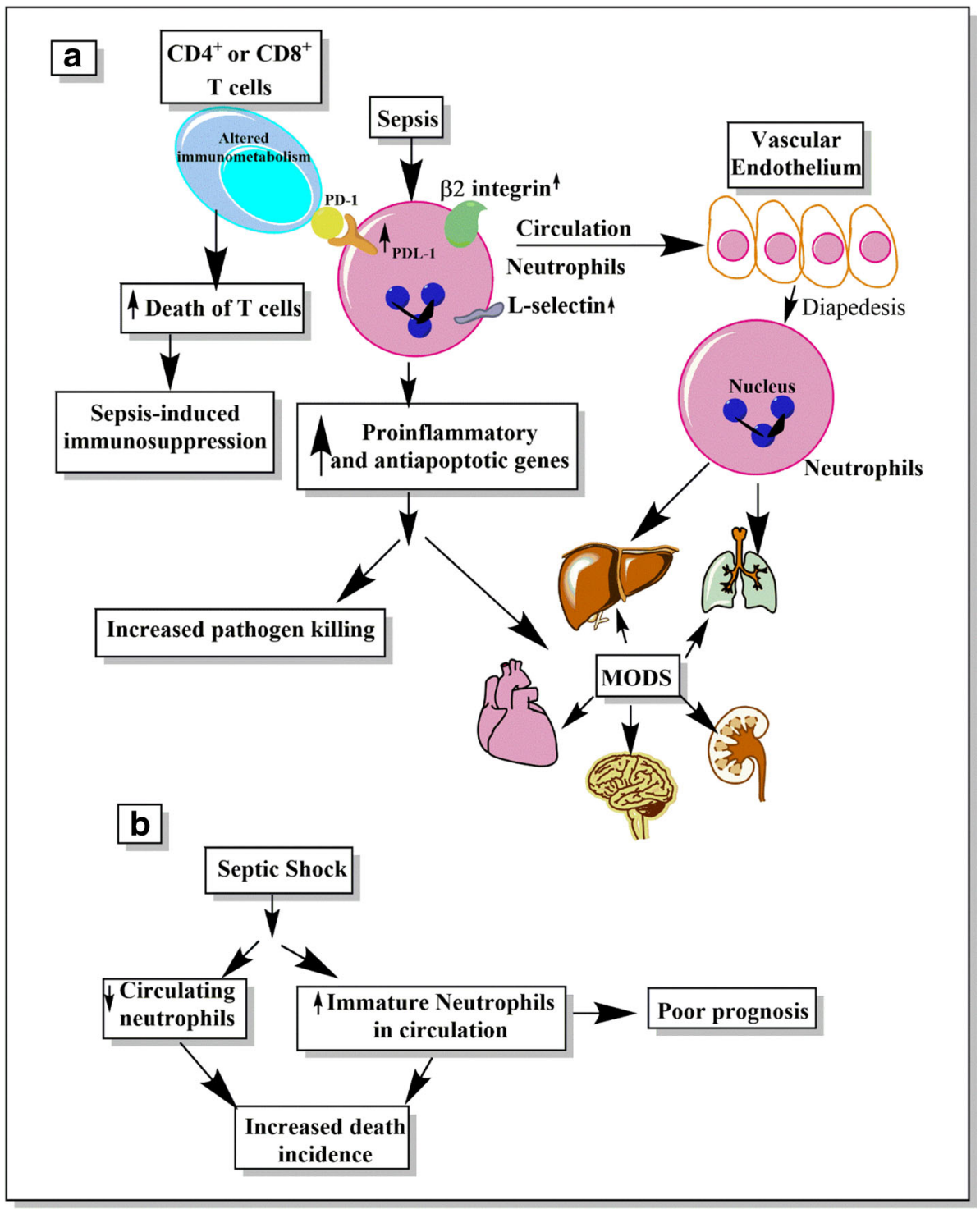

Fig. 1. Schematic representation of neutrophils in sepsis and septic shock. a Pro-inflammatory stimuli including pathogens and other pro-inflammatory factors generated during sepsis cause an activation of neutrophils in systemic circulation. This activation of neutrophils during sepsis causes an upregulation of genes involved in inflammatory cascade and anti-apoptotic activities causing a long-term survival of neutrophils and thus increasing their antimicrobial action via increased phagocytosis and pathogen killing via the generation of higher amount of ROS. However, if left uncontrolled as seen during sepsis, an increased migration of neutrophils via vascular endothelium occurs to various target organs leading to the development of MODS as a result of their bystander tissue damaging action. The increased diapedesis of neutrophils occurs due the overexpression of adhesion molecules (i.e., $\beta$ integrin and L-selectin on neutrophils) and their cognate adhesion molecules on endothelial cells (ICAM-1, VCAM-1 etc.) during sepsis. Additionally, an increased expression of PDL1 is observed in neutrophils isolated form sepsis patients that causes the apoptotic death of PD- 1 expressing $\mathrm{CD} 4^{+}$and $\mathrm{CD} 8^{+} \mathrm{T}$ cells contributing to the development of sepsis-induced immunosuppression along with other immunosuppressive mechanisms. The interaction between PD-1 and PDL-1 causes an altered stage of immunometabolism in these T cells and also inhibits the PI3K/AKT-dependent mTOR signaling, ZAP70-ERK signaling, CK2 activity, and PTEN activity. b During septic shock, the number of circulating neutrophils decrease due the their increased apoptotic death. However, the number of circulating immature neutrophils showing defective pathogen killing and clearance increase. The increased number of immature neutrophils in the circulation contribute to poor prognosis of the sepsis. While, both the decrease in circulating mature neutrophils and increased number of immature neutrophils in the circulation contribute the MODS and increase the mortality among sepsis patients. 
isolated from pediatric patients of sepsis exhibit the upregulation of genes responsible for mitochondrial dysfunction and dysregulation of redox-signaling pathways [105]. The reciprocal upregulation of $\beta 2$ integrins and L-selectin on the neutrophil surface and their cognate ligands on the endothelial cells result in margination and the egression of the neutrophils from the vasculature into the tissues (Fig. 1a) [106, 107].

The prior depletion of neutrophils before the onset of cecal ligation and puncture (CLP)-induced sepsis increases the mortality among experimental animals [108]. While their blockage or depletion after $12 \mathrm{~h}$ of onset of sepsis increases bacterial clearance and the survival of the animals [108]. However, a decrease in circulating neutrophils is observed in more severe form of the sepsis called septic shock due to an increased apoptotic death and lesser production of neutrophils in the bone marrow during septic shock (Fig. 1b) [109, 110]. While an increased level of immature neutrophils in the circulation is also associated with a severity of the sepsis and may lead to poor prognosis (Fig. 1b) [111]. Thus, this increase in immature granulocytes in the peripheral circulation is directly associated with an increased death of the patients with septic shock (Fig. 1b) [112]. This is because the immature neutrophils are laden with the higher levels of elastase, cathepsins G, and myeloperoxidase (MPO) that are effective in killing the invading pathogen but also cause bystander inflammatory tissue or organ damage and increase the degree of organ failure and mortality among sepsis patients $[113,114]$. These neutrophil serine proteases (NSPs) also cause thrombus formation inside the blood vessel that may play an important role in the induction of disseminated intravascular coagulation (DISC) [113, 114]. Additionally, the process of Netosis is also involved in sepsis or septic shock-induced DISC $[115,116]$. Thus, neutrophils are two edge sword immune cells that in one way provide protection against invading pathogens and another way cause MODS and DISC during sepsis.

\section{Neutrophil Immunometabolism During Sepsis}

Pathogenic and pro-inflammatory stimuli of neutrophils during infections leading to the development of sepsis also cause metabolic changes among them by increasing the process of aerobic glycolysis and an increased utilization of glucose as an energy source, while the FA or lipid metabolism is required for the neutrophil development [117-119]. Adult mice with FAS deficiency induced by tamoxifen-inducible global deletion of FAS die off due to systemic endotoxemia or sepsis due to dysbiosis of intestinal bacteria in response to disruption of intestinal barrier function and severe neutropenia [118]. The FAS deficiency causes neutropenia due to the induction of high endoplasmic reticulum (ER) stress and apoptosis via specifically affecting the membrane content of peroxisomederived ether lipids [118]. Thus, lipid metabolism is important for the generation of neutrophils in the bone marrow, while glycolysis and pentose phosphate pathway (PPP) are important for their immune function (Fig. 2).

The immunometabolic shift (i.e., glycolytic reprogramming) among neutrophils was reported as early as during 1980s [77]. An increased flux of glucose via the parallel PPP is also observed to support the increased production of the reducing equivalent NADPH that acts as cofactor for NADPH oxidase enzyme involved in antimicrobial action (Fig. 4) [120, 121]. While, glycolysis is mainly required for the regulation of important function of neutrophils including oxidative burst, calcium $\left(\mathrm{Ca}^{2+}\right)$ mobilization, and chemotaxis [122]. Thus, neutrophils primarily use glycolysis and PPP as a major energy source due to the lesser numbers of mitochondria that are not involved in ATP synthesis but maintain the redox balance required for their survival (Fig. 3) [120]. The process is deemed to be coupled with the increased consumption of non-mitochondrial oxygen and allows the synthesis of ROS, an essential component of neutrophils to kill the pathogens $[121,123,124]$. The increased uptake of glucose through increased GLUT1 expression, aerobic glycolysis, and a metabolic shift towards PPP are essential for the formation and release of neutrophil extracellular traps (NETs) due to the involvement of glucose-6phosphate dehydrogenase (G6PD), an important enzyme from PPP fuelling the NADPH oxidase with NADPH to synthesize superoxide [125-127]. The NADPHindependent production of mitochondrial ROS, the glutamine uptake and its metabolism are not required for the process of Netosis or NET formation and its release [125, 127]. An impairment in the process of aerobic glycolysis in neutrophils also inhibits their tendency to form NETs that are composed of mixture of DNA, histone proteins, and antimicrobial peptides [127]. For example, 2-deoxyglucose (2-DG), an inhibitor of glycolysis and ATP synthase inhibitor called oligomycin both inhibit the process of Netosis [127]. Thus, neutrophils are mainly dependent on glycolysis for their energy requirement instead of OXPHOS due to relatively low number of functional mitochondria as compared to macrophages/monocytes that play an important role in neutrophil apoptosis but not in increased oxidation of glucose reflecting the phenomenon of Warburg effect [120,128, 129]. The neutrophil 


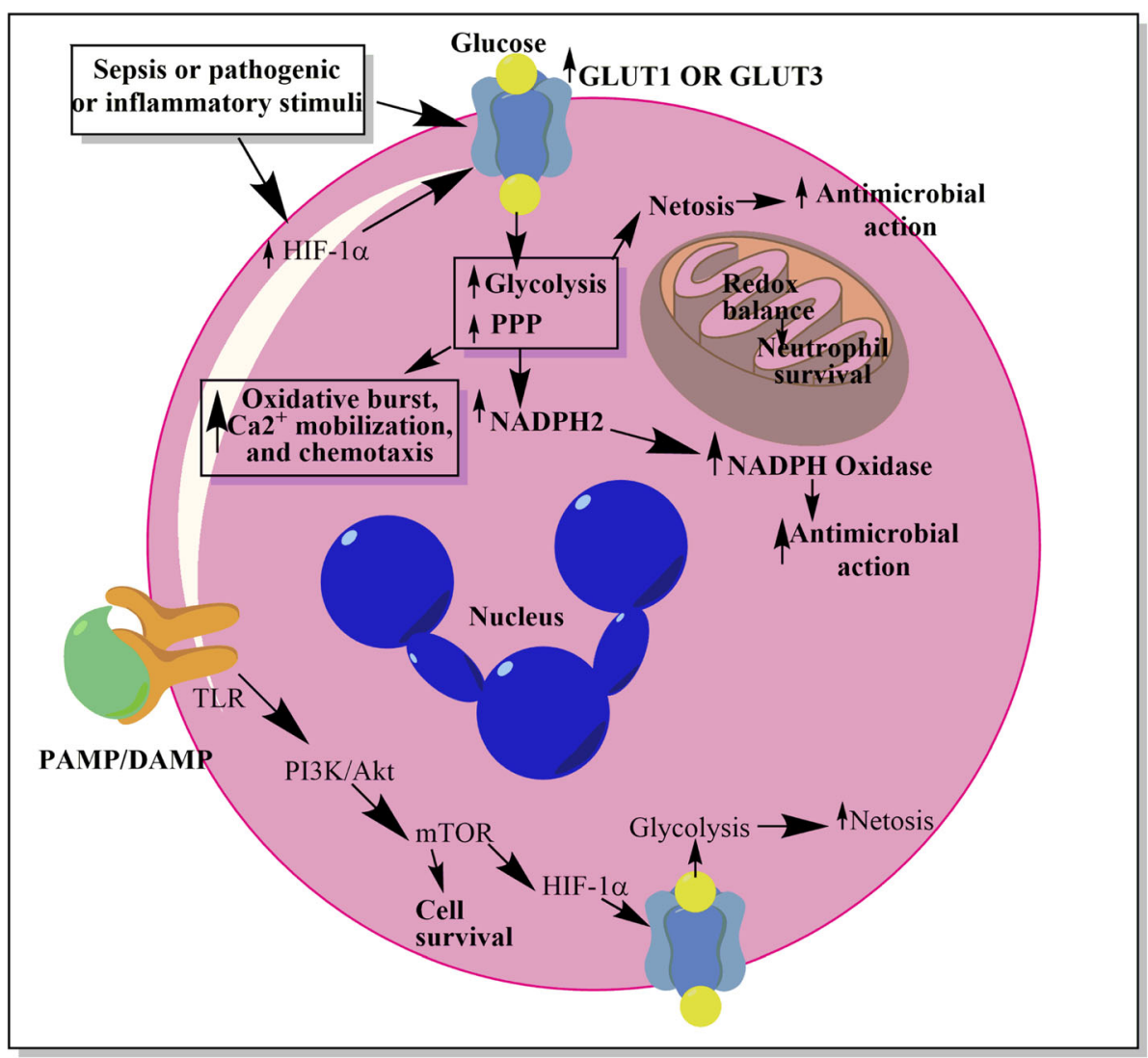

Fig. 2. Neutrophil immunometabolism during sepsis. The neutrophil immunometabolism shifts towards an increased glycolysis strengthened by PPP leading to the synthesis of reduced NADH or NADH2. NADH2 acts as cofactor for NADH-oxidase that increases the antimicrobial action of neutrophils. The demand for increased glucose for glycolysis and PPP is fulfilled by an increased expression of GLUT1 and GLUT3 in response to increased synthesis of HIF$1 \alpha$ and mTOR signaling. The increase in glycolysis and PPP also enhances the increase mobilization of $\mathrm{Ca}^{2+}$, oxidative burst, and neutrophil chemotaxis at site of infection and inflammation. mTOR signaling and glycolysis are also responsible for the formation of neutrophil extracellular traps (NETs) contributing to their antimicrobial action. The PI3K/Akt pathway activated downstream to TLR signaling in neutrophils increases the mTOR signaling causing HIF-1 $\alpha$ activation that further enhances glycolysis and NET formation or Netosis.

mitochondria are required for the maintenance of their shape as the inhibition of mitochondrial function by FCCP (Trifluoromethoxy carbonylcyanide phenylhydrazone, a potent uncoupler of oxidative phosphorylation in mitochondria that disrupts ATP synthesis by transporting protons across cell membranes) or oligomycin resulted in the change of their shape within 2 min [130]. However, an increase in the duration of the presence of these inhibitors to $2 \mathrm{~h}$ inhibited their chemotaxis potential and respiratory burst [130]. Thus, the intact mitochondrial function in neutrophils is important to maintain some functions, but not for the rapid processes including pathogen phagocytosis and respiratory burst. For example, neutrophil mitochondria maintain their membrane potential via glycerol 3-phosphate shuttle, a pathway that allows the receipt of electrons from glycolysis by complex III of the electron transport chain [131]. This high commitment towards the maintenance of Warburg effect may be responsible for the maintenance of temporary viability of neutrophil event during the process of Netosis [132].

The activation of hypoxia-inducible factor- $1 \alpha$ (HIF$1 \alpha)$ and mTOR signaling pathways serves as major regulators of glycolysis in neutrophils (Fig. 2) [133, 134]. HIF$1 \alpha$ increases the activity and expression of GLUT1 and GLUT3 on neutrophils and thus the uptake of glucose, glucose metabolism by upregulating the enzymes hexokinase 2 (HK2) and phosphofructokinase B3 (PFKFB3), and ATP synthesis [135-137]. HIF- $1 \alpha$ also serves as a major controller of the expression of antimicrobial molecules (i.e., granule peptides, antimicrobial peptides (AMPs), 


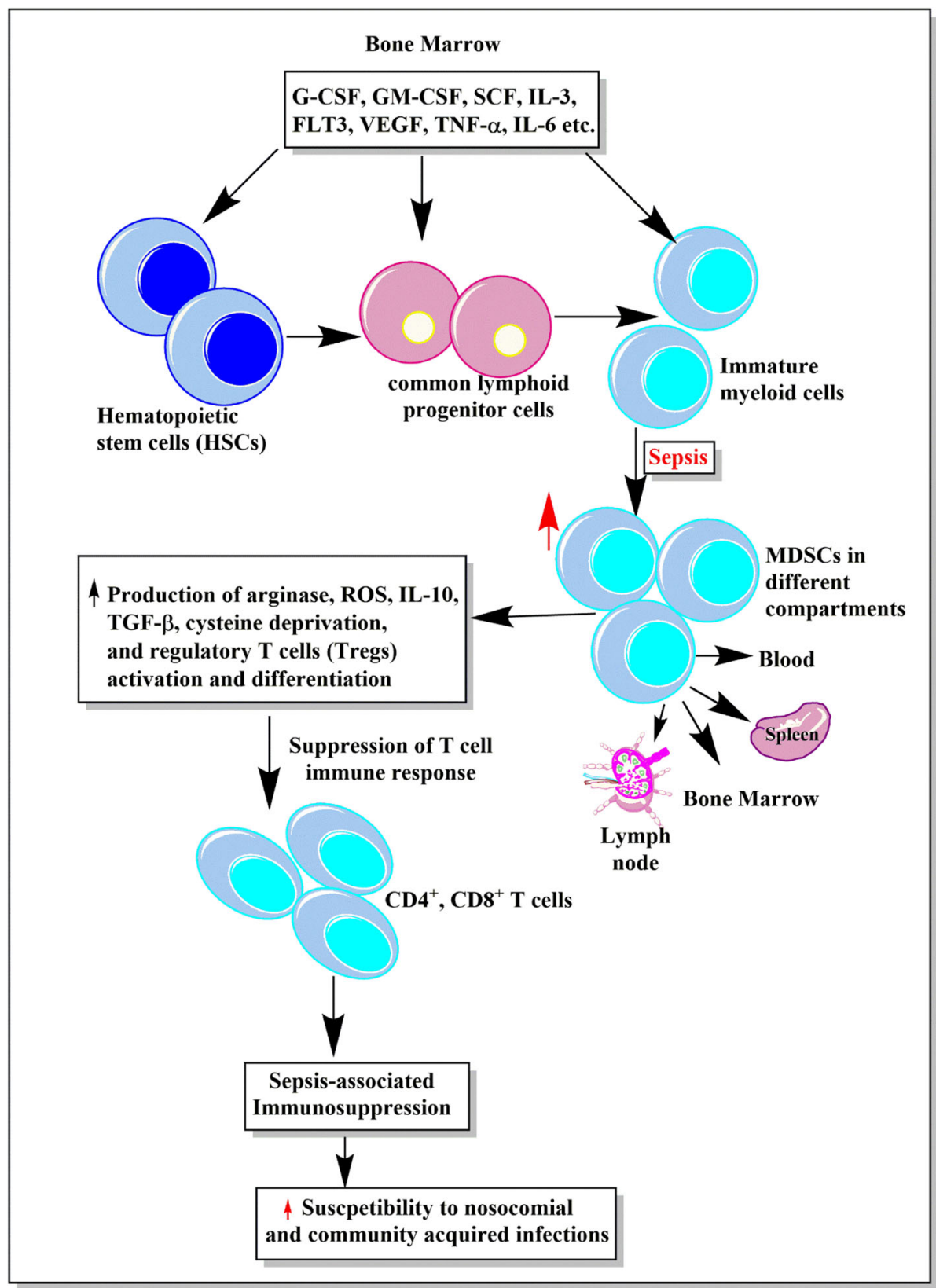

Fig. 3. Expansion of MDSCs during sepsis and induction of immunosuppression. MDSCs are generated and expanded rapidly from immature myeloid cells upon encountering pathogens and inflammogens. Both these factors, infection and inflammatory cytokines, are present in systemic circulation and target organs including the liver, lungs, sepsis, kidneys, and brain etc. Thus, MDSCs are increased in circulation, bone marrow, spleen, and lymph nodes. MDSCs secrete various immunosuppressive molecules including IL-10 and TGF- $\beta$, mentioned in text in detail to exert their immunosuppressive action on CD4 ${ }^{+}$, $\mathrm{CD} 8^{+} \mathrm{T}$ cells as well as polarizing them to exert Th2 immune response. The induction of MDSCs-derived suppression of $\mathrm{T}$ cell immune response adds in further in the sepsis-induced immunosuppression responsible for the increased susceptibility of the sepsis patient to acquired nosocomial and communityacquired infections.

NO, and TNF- $\alpha$ ) by neutrophils [138]. The deficiency of HIF- $1 \alpha$ in neutrophils makes laboratory mice more susceptible to Staphylococcus aureus-induced sepsis that further indicates its requirement for glycolysis controlling 


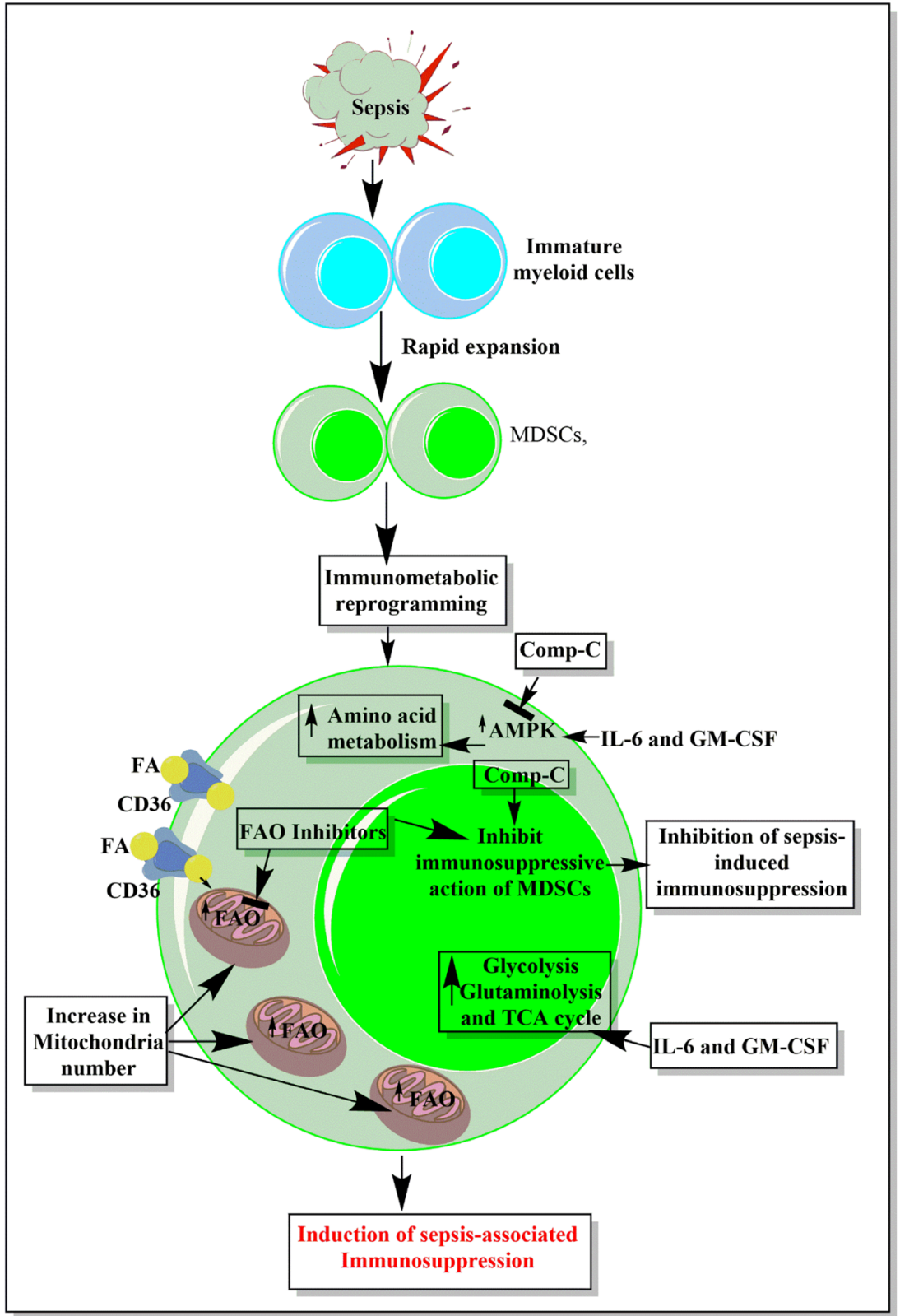

Fig. 4. Immunometabolism in MDSCs during sepsis. The rapid expansion of MDSCs during sepsis causes an increase in FAO due to increased uptake of FAs via an increased expression of $\mathrm{CD} 36$ or lipid uptake receptor. The FAO is further supported by an increased expression of enzymes required for FAO. Along with increased FAO, amino acid (AA) metabolism is also increased. The inhibition of FAO through FAO inhibitor inhibits the immunosuppressive action of MDSCs. In addition to FAO and AA metabolism, glycolysis, glutaminolysis, and TCA cycle is also increased in the presence of IL-6 and GM-CSF. An increase in AMPK level is also observed and the inhibition of AMPK via compound-C (Comp-C) causes an inhibition of AA metabolism and thus the MDSCs-mediated immunosuppression.

neutrophil effector function to contain infection and thus the development of sepsis $[139,140]$.

The mTOR signaling is one of several regulators of metabolic pathways in neutrophils controlling glycolysis via enhancing the expression of HIF-1 $\alpha$ (Fig. 2) [139, 141]. The mTOR signaling is initiated as a downstream target of PI3K/AKT signaling pathway upon inflammatory stimuli including TLR stimulation (Fig. 2) [142] and 
contributes to the cell survival [120]. The mTORC2 signaling plays an important role in the neutrophil polarization in response to different chemoattractants and its loss of function by the silencing of Rictor inhibits this process of neutrophil polarization [143]. The production of NETs from dying neutrophils during infection or sepsis is supported by (HIF- $1 \alpha$ ) and mTOR as the inhibition of both the molecules inhibits the process of NETosis [144, 145]. Further, the inhibition of mTOR with high dose of Rapamycin prevents the stimulatory action of IL-23 on neutrophils to synthesize IL-17 and IL-22 [146]. Thus, the altered neutrophil immunometabolism play an important role in the pathogenesis of sepsis and the associated immune response. However, its targeting needs a caution depending on the immune status of the sepsis patients and severity of the disease.

\section{Myeloid-Derived Suppressor Cells (MDSCs) and the Alteration of Their Immunometabolic Stage During Sepsis}

MDSCs are heterogeneous $\mathrm{CD} 11 \mathrm{~b}^{+} \mathrm{Gr} 1^{+}$cell population of immature innate immune cells with granulocytic and monocytic progenitors and expand during inflammatory conditions including cancer and infections [147-150]. These cells act as potent immunosuppressor cells for antigen-specific $\mathrm{CD}^{+}$and $\mathrm{CD}^{+} \mathrm{T}$ cells via different mechanisms including the production of arginase, ROS, IL-10, transforming growth factor- $\beta$ (TGF- $\beta$ ), cysteine deprivation, and regulatory $T$ cells (Tregs) activation and differentiation (Fig. 3) [148, $150,151]$. Thus, MDSCs are potent immunosuppressive innate immune cells. A gradual increase in the circulating

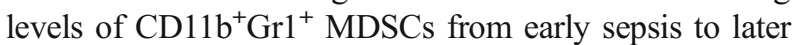
stages of sepsis has been observed (i.e., sepsis-associated immunosuppression) (Fig. 3) [152]. The adoptive transfer of early (day 3) sepsis-derived MDSCs, into naïve mice after CLP led to the increased production of proinflammatory cytokines, decrease in growth of bacteria in the peritoneal cavity, and increase in their mortality [152]. However an increase in the survival of septic mice was observed upon adoptive transfer of late stage (day 12) sepsis-derived MDSCs. This difference can be explained as early MDSCs express higher levels of nitric oxide (NO·) and pro-inflammatory cytokines, while late MDSCs express a higher level of anti-inflammatory molecules including arginase, IL-10, and TGF- $\beta$ [152]. Furthermore, late MDSCs have more $\mathrm{CD} 31^{+}$myeloid progenitors and upon treatment with granulocyte-macrophages colony stimulating factor (GM-CSF) generate a lesser number of macrophages and DCs in comparison to early MDSCs. Thus, with the progression of sepsis, the number of proinflammatory MDSCs decrease and the number of immunosuppressive or anti-inflammatory MDSCs increase [152]. In addition to suppression of $\mathrm{T}$ cell function, they also polarize $\mathrm{T}$ cell immune response towards $\mathrm{Th} 2 \mathrm{immu}-$ nity during polymicrobial sepsis and their number increases in spleen, bone marrow, and lymph nodes (Fig. 3) $[153,154]$. However, another study indicated that both early (3 days) and late (10 days) sepsis-derived MDSCs are immunosuppressive and making their function in animal model of sepsis controversial $[154,155]$. This can be explained on the difference in the days of isolation of MDSCs during late sepsis, i.e., 10th day and 12th day post sepsis. However, the exact mechanism needs to be identified.

MDSCs in humans are characterized differently as $\mathrm{CD} 14^{-} \mathrm{CD} 11 \mathrm{~b}^{+}$cells [156]. Human MDSCs may express $\mathrm{CD} 15$ or $\mathrm{CD} 33$ but lack the markers for mature myeloid and lymphoid cells along with HLA-DR expression. $\mathrm{Hu}-$ man cases of sepsis also show an expansion in the population of MDSCs during sepsis-associated immunosuppression causing an enhanced susceptibility to nosocomial infections in patients admitted to the ICUs (Fig. 4) [157]. In human cases of sepsis, granulocytic MDSCs (GMDSCs) producing arginase 1 (Arg-1) and S100A12 are responsible for the higher incidence of nosocomial infections and play a major role in the sepsis-associated immunosuppression. However, both G-MDSCs $\left(\mathrm{CD} 14^{-} \mathrm{CD} 15^{+}\right)$ and M-MDSCs (monocytic MDSCs, CD14 $4^{+} \mathrm{HLA}-\mathrm{DR}^{\text {low } /}$ ${ }^{-}$) are highly involved in T cell dysfunction in human cases of sepsis [157]. In addition, plasma levels of MDSCs mediators including S100A8/A9, S100A12, and arginase 1 are highly increased in sepsis patients. Thus, MDSCs are important innate immune cells playing a crucial role in the pathogenesis of sepsis.

\section{MDSC Immunometabolism in Sepsis}

The rapid expansion of MDSCs is seen in various inflammatory conditions including cancers, autoimmune diseases, and infectious diseases including viral (i.e., Hepatitis $\mathrm{C}$ virus (HCV) and $\mathrm{HIV}$ infections etc.) and bacterial infections, and sepsis $[148,149,156,158-162]$. The process of rapid expansion of MDSCs is induced by various factors including G-CSF, GM-CSF, PGE2, TGF- $\beta$, MCSF (Monocyte colony stimulating factor), IL-3, VEGF (vascular endothelial factor), IL-1 $\beta$, IL-6 IL-4, IL-10, IL13 , and IFN- $\gamma$ [163-165]. The rapid expansion of these MDSCs exert an impact on immunometabolic 
reprogramming of these cells. For example, an increase in FAO is observed in MDSCs of peripheral blood circulation and exhibits an increased FA uptakes via increased expression of CD36 (Lipid uptake receptor), increase in number of mitochondria, increased activity of FAO enzymes including CPT1 and 3-hydroxyacyl-CoA dehydrogenase (HADHA), and an increase in the oxygen consumption rate (Fig. 4) $[15,164]$. This is further strengthened by the observation that a pharmacological inhibition of FAO in MDSCs inhibits their immunosuppressive or immunoregulatory action $[15,166]$. Additionally, amino acid metabolism, i.e., L-arginine either via ariginase-1 (Arg-1) or inducible nitric oxide synthase (iNOS) further increases their immunosuppressive action via suppressing $\mathrm{T}$ cell function $[151,167]$. The NO produced via iNOS activity causes the nitration of tyrosine and S-cysteine of various proteins causing the death of the T cells [164].

In addition to FAO and amino acid metabolism, MDSC generated in the presence of IL- 6 and GM-CSF exhibit an increased glycolysis, glutaminolysis, and Krebs or TCA cycle (A. et al., 2017; [168]). An upregulation in the AMPK (5' adenosine-activated monophosphate kinase) levels and its activity are also reported in mature MDSCs generated in vitro in the presence of IL- 6 and GM-CSF but the association of MDSC AMPK with specific metabolic pathway is not reported yet [169]. However, the inhibition of AMPK in MDSCs by a specific compound called compound C (CompC) inhibited the L-arginine metabolizing enzymes and thus, their immunosuppressive action (Fig. 4) [169]. HIF-1 $\alpha$ is also shown to control the immunosuppressive function of via regulating their differentiation and maturation [170]. For example, it controls the expression of PDL-1 on MDSCs and thus the apoptosis of PD-1 expressing antigen-specific $\mathrm{CD} 8^{+}$ T cells $[170,171]$. Thus, blocking MDSC HIF- $1 \alpha$ and PDL-1 inhibits the process of $\mathrm{T}$ cell-mediated immunosuppression observed in sepsis and can have an implication in targeting sepsis-associated immunosupression. Further studies regarding MDSC immunometabolism in context to sepsis are required for understanding and regulating sepsis-associated immunosuppression.

\section{Endothelial Cells (ECs) and Their Immunometabolism During Sepsis}

ECs form the single cell layer called endothelium lining the blood vessels and lymphatic vessels forming the semipermeable membrane between blood and lymph [40]. In addition, they also comprise the vital organ including the liver, kidney, lungs, and heart [172]. Due to the secretion of various cytokines and chemokines in response to various PAMPs and DAMPs recognized by different PRRs expressed by them and the expression of both major histocompatibility complex (MHC) class I and II molecules required for antigen presentation to T cells, ECs are also considered as conditional innate immune cells [40]. Hence, circulating pathogens, PAMPs, and DAMPs also cause immunological stimulation of ECs during sepsis causing an increased expression of adhesion molecules including ICAM-1 (Intracellular adhesion molecule-1), VCAM-1 (Vascular cell adhesion molecule-1), and various integrins required for neutrophil and monocyte migration at the site of infection $[38,40,173]$. The profound activation of ECs leads to their dysfunction during sepsis and is involved in the sepsis-associated MODS and septic shock (Fig. 5) [43-45]. Even NF-kB activation in ECs is shown as a major deriver for the escalation of inflammation responsible for the induction of sepsis [174]. The M2 isoform of pyruvate kinase (PKM2) is found to be highly expressed in ECs over PKM1 [175]. It controls suppression of tumor suppressor gene $\mathrm{p} 53$ and maintains the cell cycle progression in proliferating ECs. However, in quiescent and nonproliferative ECs, it regulates endothelial barrier integration and functions independent of its canonical function as a pyruvate kinase as its inhibition causes degeneration of vascular endothelial barrier via damaging tight junction and inducing vascular leakage [175]. The regulation of vascular endothelial barrier function by PKM2 involves the inhibition of NF- $\mathrm{kB}$ and its downstream target molecules called angiopoietin 2 (Ang-2) [175]. The overactivation and overproduction of Angiopoietin-2 causes the inhibition of Tie2 signaling (Tie2 activation under maintains the quiescent state in ECs of the vascular endothelium characterized by dynamic barrier function and decreases expression of adhesion molecules for circulating leukocytes) causing the induction of sepsis-associated vascular leak and development of septic shock [176-178]. The inhibition of PKM2 in vivo in mice causes the induction of vascular leakage-associated with sepsis, increased bacteremia, and higher mortality [175]. Thus, it will be interesting to observe both enzymatic and non-enzymatic functions of PKM2 in ECs during sepsis and its impact their immunometabolism. The EC activation during sepsis also leads to the immunometabolic reprogramming among these cells.

\section{Immunometabolic Reprogramming Among MDSCs During Sepsis}

ECs are mainly dependent on glycolysis for their energy demand under homeostatic or normal condition 


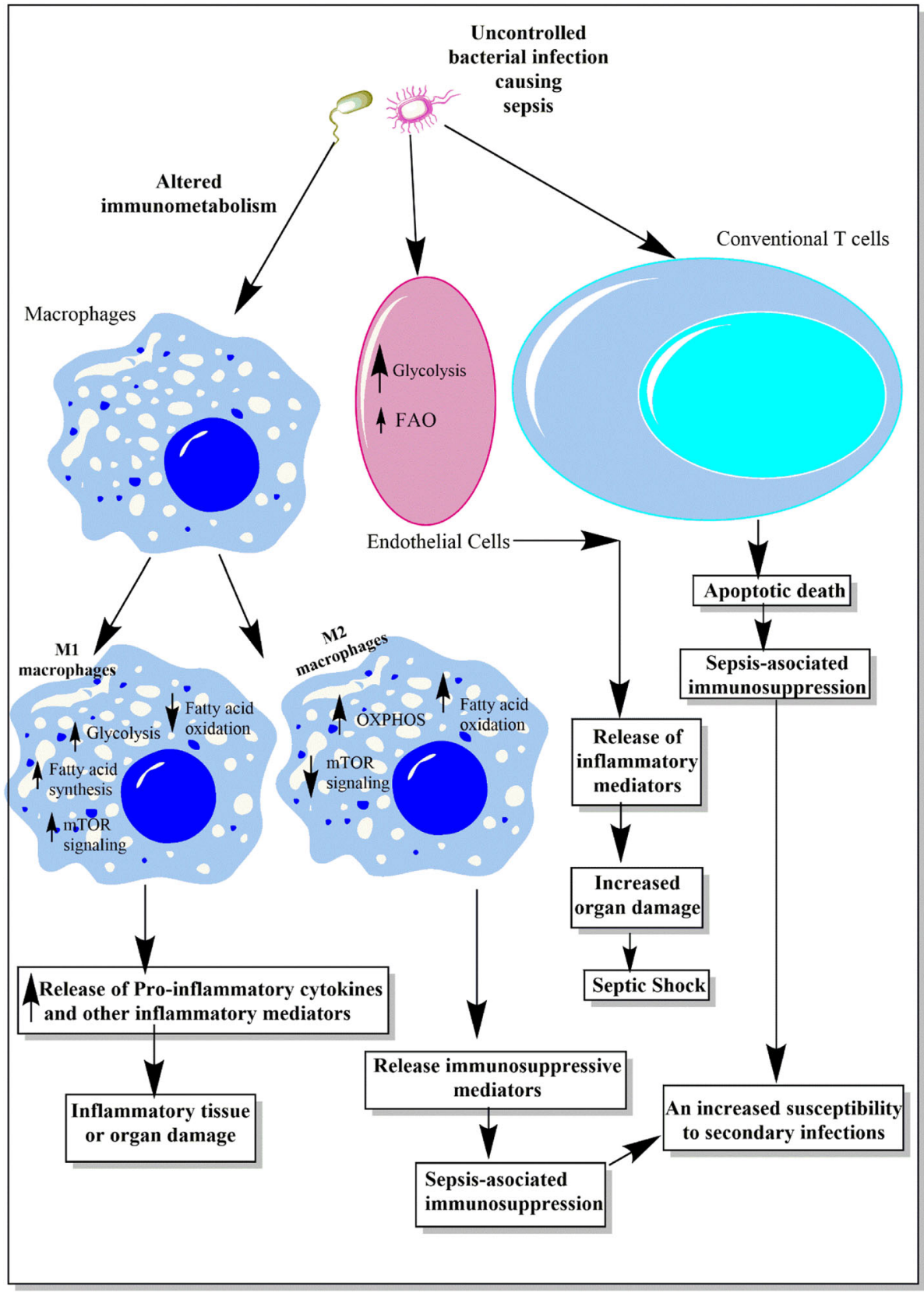

Fig. 5. Schematic representation of impact of sepsis on immunometabolism. Sepsis is result of dysregulated immune response responsible for organ damage. This dysregulation of immune response is also governed by immunometabolic stage of immune cells that is macrophages, endothelial cells (ECs), and T cells. For example, under homeostasis, macrophages and T cells use OXPHOS for their energy demand, while ECs use glycolysis. However, sepsis leads to the reprogramming of the immunometabolism and M1 macrophages exhibit an increased glycolysis, fatty acid synthesis (FAS), and mTOR signaling. While, M2 macrophages show an increased OXPHOS and fatty acid oxidation (FAO) with a decreased mTOR signaling. The process of glycolysis is further increased in ECs during sepsis that aggravates their pro-inflammatory action and the organ damage. Sepsis also causes the early death of conventional $\mathrm{T}$ cells therefore along with the induction of M2 macrophages, this leads to the development of sepsis-associated immunosuppression responsible for susceptibility to secondary infection. 
instead of OXPHOS used by other innate immune cells and the glycolysis is increased during inflammatory conditions including cancer and sepsis (Fig. 5) [76]. Only $15 \%$ or less ATP generation of ECs occur via oxidation of glucose, glutamine, and FAs and serve as anaplerotic substrates for the TCA cycle $[179,180]$. Anaplerosis can be defined as a process by which glucose, glutamine or amino acids replenish the TCA cycle [181]. Glutaminase (GLS) catalyzes the conversion of glutamine to glutamate and ammonia in a phosphate-dependent manner, and increased GLS flux is reported in ECs [182]. A higher level of GLS is observed in ECs as compared to other immune cells [183]. The inhibition of GLS activity induces EC senescence and needs to be checked during sepsis as endothelial dysfunction is associated with sepsis and septic shock [184]. FAO also serves as an important energy source for ECs and an increased expression of CPT1A is observed in ECs for the transportation of FAs into mitochondria for FAO and dNTP synthesis $[185,186]$. The inhibition of EC FAO via the blockage of CPT1A improves their dysfunction during ocular angiogenesis and needs an attention to target ECs during sepsis and septic shock. Induction of hypoxia in ECs promotes both glycolysis and glutaminolysis but causes a decrease in FAO and an increase in FAS [187]. ECs exhibit the hypoxia during sepsis and can be responsible for sepsis-associated endothelium dysfunction [44]. Thus, an inhibition of hypoxia in ECs may inhibit an increased glycolysis in ECs during sepsis that induces their pro-inflammatory damage and sepsis-induced vascular leakage causing development of, MODS, septic shock and death of the patient.

Vascular endothelial growth factor (VEGF)-mediated stimulation of ECs doubles the glucose influx and thus doubles the glycolytic rate to overcome the increased energy demand [76]. An increased systemic level of VEGF is reported in patients with sepsis, while its low concentration is associated with an increased hematological and renal damage [188-190]. Thus, this alteration in levels of VEGF depending on the severity of the sepsis may lead to EC damage causing vascular leak and organ damage during sepsis. VEGF levels in systemic circulation have shown a great prognostic value for sepsis syndrome [191]. Thus, any change in the metabolic stages of immune cells can promote an aberrant immune response that can be its overactivation or immunosuppression (Fig. 5). Both these stages of the immune response that are hyperactivation and immunosuppression are observed during sepsis initially but at later stages of sepsis immunosuppression is a major phenotype. A direct anti-VEGF antibody-based or a pharmacological inhibitor of VEGF may have direct potential to fix back the immunometabolic reprogramming of ECs and thus their pro-inflammatory function responsible for vascular leakage, MODS, septic shock and death of the patient. Further studies may prove beneficial in the direction.

\section{Macrophage Immunometabolism During Sepsis}

Macrophages are potent innate immune cells playing important role in the defense against invading pathogens and the generation of pro-inflammatory immune response. Under normal homeostatic conditions or in the absence of any pathogen or potential inflammogens, macrophages are dependent of OXPHOS for their energy requirement through the utilization of glucose as energy source [80, 192]. But an encounter with pathogens or their PAMPs induces a shift in immunometabolic programming in macrophages that includes a shift from OXPHOS to glycolysis and this phenomenon is called Warburg effect [77, 80, 193]. This increased glycolysis is maintained by an increase in the membrane expression of GLUT1 required for an increased glucose import and NO generation [194, 195]. The increase in glycolysis is accompanied by an increase in FAS and glutaminolysis; thus, the macrophages with increased glycolysis, glutaminolysis, and FAS exhibit a pro-inflammatory phenotype called M1 macrophages or classically activated macrophages (CAMs) and secrete various pro-inflammatory cytokines and molecules required to clear the pathogens but their uncontrolled activation causes pro-inflammatory damage to tissues and organs (Fig. 5) [196]. An induction of alternatively activated macrophages (AAMs) or M2 macrophages during later stages of sepsis may further aggravate the immunosuppression observed [197, 198]. The M2 macrophages isolated from septic patients exhibit a decreased expression of HLA-DR and CD86 (costimulatory molecule and M1 marker) in addition to a higher expression of CD163 and CD206 [197]. The M2 macrophages show an increase in OXPHOS and FAS with a decrease in mTOR signaling leading to the induction of anti-inflammatory phenotype and further enhancing the sepsis-associated immunosuppression. The detailed macrophage immunometabolism in context to sepsis is beyond the scope of the present article and is already discussed in detail by the author [199].

\section{T Cell Immunometabolism Reprogramming During Sepsis}

An increased loss of $\mathrm{CD} 4^{+}, \mathrm{CD} 8^{+}$, and $\mathrm{CD} 4^{+} \mathrm{CD} 8^{+} \mathrm{T}$ cells is observed during sepsis in both mice models and in humans causing a simultaneous immunosuppression [200- 
203]. Similar to naïve macrophages, naïve $\mathrm{CD} 4^{+}$and $\mathrm{CD} 8^{+}$ $\mathrm{T}$ cells are dependent on OXPHOS for their energy requirement that is dependent on glucose via the process of glycolysis, FAO, and glutaminolysis. The glucose uptake is maintained by the process of Tonic TCR signaling required for the survival of naïve $\mathrm{T}$ cells $[204$, 205]. However, $T$ cells isolated form sepsis patient show defective OXPHOS, glycolysis, and glutaminolysis and are unable to restore their normal immunometabolic stage even in the presence of glucose [206]. The alteration of glucose uptake by these T cells is shown to be dependent of mTOR signaling and AMPK1 $\alpha$ phosphorylation [206]. A defective IL-7R signaling due to lowest levels of IL-7 in sepsis patients is responsible for the defective immunometabolic stage of these convention $\mathrm{T}$ cells and their apoptotic death during early stages of sepsis due the defective expression of GLUT1 required for glucose intake [207-209].

Regulatory $\mathrm{T}$ (Tregs) cells under in vitro conditions are dependent on lipid peroxidation (LPO) or FAO for their energy requirement and have higher number of mitochondria instead of glycolysis observed in effector $\mathrm{T}$ cells (Teffs) $[210,211]$. But in vivo Tregs are dependent on glycolysis-mediated lipid synthesis or FAS for their growth, proliferation, and survival $[212,213]$. An increased number of Tregs along with the decrease in the population of conventional $\mathrm{T}$ cells during sepsis is responsible for the generation of sepsis-induced immunosuppression. The discussion of immunometabolic factor influencing the immunometabolism of Tregs and conventional $\mathrm{T}$ cells is beyond the scope of this article and is discussed by the author somewhere else [214]. Thus, an altered immunometabolism among immune cells during sepsis controls their immunologic functions involved in the pathogenesis of sepsis.

\section{IMMUNOMETABOLIC REPROGRAMMING IN CASES OF CLINICAL SEPSIS}

Transcriptional reprogramming of metabolic pathways in critically ill sepsis patients is reported recently [215]. According to these authors, critically ill patients reported an upregulation of enzymes involved in the glycolytic pathway [215]. For example, all the three isoforms of the enzyme hexokinase (HK) (HK1, HK2, and HK3) were upregulated in critically ill patients. HK is involved in the conversion of glucose into glucose-6-phosphate, the very first step in the glycolysis pathway. An increase in pyruvate kinase M2 (PKM2) is also observed. This enzyme is involved in the final step of glycolysis that is a synthesis of pyruvic acid (pyruvate) and adenosine triphosphate (ATP) molecules [215]. In addition to an upregulation of glycolytic enzymes, an overexpression of glucose transporter gene called SLC2A3 is also reported [215]. Furthermore, an increase in glycolysis in macrophages during sepsis-like conditions is also supported by an increase in the expression GLUT1 [194] that promotes an increased glucose uptake required for shifting cellular metabolism from OXPHOS to glycolysis. However, an increased level of lactate dehydrogenase A (LDHA) is also observed [215]. This enzyme catalyzes the conversion of pyruvate to lactate. This increased expression of LDHA is accompanied by an overexpression of $S L C 16 A 3$ gene that encodes for monocarboxylate transporter 4 protein shuttling lactate out of the cell, thus creating a proinflammatory extracellular environment. Along with this increase in glycolytic enzymes, a decrease in both the isoforms of phosphofructokinase (PFK) called phosphofructokinase $\mathrm{M}$ (PFKM) and phosphofructokinase L (PFKL) is also reported in septic patients [215]. An upregulation of two other enzymes called glucose-6phosphatedyhydrogenase (G6PD) and phosphogluconate dehydrogenase (PGD) is also reported [215], indicating an upregulation of pentose phosphate pathway (PPP). Thus, sepsis causes an alteration of normal immunometabolism of circulating immune cells during sepsis via an increased glycolysis and PPP as indicated by both animal model of the disease and clinical cases of sepsis.

\section{THERAPEUTIC TARGETING OF IMMUNOMETABOLISM DURING SEPSIS}

Immunometabolism has been extensively studied during cancer and effectively targeted to strengthen the existing tumor immunotherapies and other anti-cancer therapies $[16,216,217]$. However, sepsis is compared to cancer in terms of its immunopathogenesis therefore it becomes important to target immunometabolism of immune cells depending on the stage of sepsis [218, 219]. Targeting both macrophage and $\mathrm{T}$ cell (including regulatory $\mathrm{T}$ cells) immunometabolism is shown to be a novel approach to targeting sepsis [199, 214]. For example, the treatment with plumbagin (a naphthoquinone derivative obtained from the roots of Plumbago zeylanica) decreased the PKM2 activity and inhibited the increased glycolysis in macrophages [220]. The treatment also inhibited the release of pro-inflammatory cytokines during sepsis and increased the survival of mice subjected to sepsis [220]. 
A decreased activity of AMPK (a conserved serine/ threonine kinase) is reported in pro-inflammatory macrophages during inflammatory conditions [221]. Studies have shown that the introduction of a constitutively active form of AMPK- $\alpha 1$ in macrophages inhibits the proinflammatory function of macrophages [222, 223].

An activation of AMPK with an AMP analog called 5Aminoimidazole-4-carboxamide ribonucleotide (AICAR) showed a protective action in a murine model of sepsis [224, 225]. Another AMPK activator called acadesine also proved beneficial to mice suffering from sepsis [226]. This protective action of AMPK activation involves its immediate effect on the immunometabolic reprogramming of macrophages during sepsis [227]. The deficiency of AMPK in macrophages promotes aerobic glycolysis in macrophages via an increased activation of PKM2, an enzyme required for glycolysis via the release of HMGB1 [227]. A-769662 mediated activation of AMPK in macrophages inhibits the release of HMGB1 and thus, sepsis-associated inflammatory damage in mice [227]. Furthermore, shikonin (PKM2 shRNA) via inhibiting lactate production and HMGB1 release increased the survival of AMPK $\alpha-1$ deficient septic mice [227]. The antidiabetic drug called metformin is also shown to exert a protective effect in sepsis-induced acute lung injury model via activating the AMPK [228]. This metformin-mediated activation of AMPK protects from sepsis-associated lung injury via activating GSK3 $\beta$ signaling pathway that controls the chemotaxis and ability of neutrophils and macrophages to kill pathogens [229]. In addition to enhancing the activity of GSK3 $\beta$, metformin also preserves the mitochondrial complex Vor ATP synthase function and increases the amount of electron transport chain (ETC) complex III and IV [229]. The metformin treatment also inhibited the accumulation of immunosuppressive HIF- $1 \alpha$ in macrophages and the development of tolerogenic macrophages via activating AMPK. In addition to activating AMPK in macrophages, metformin-mediated activation of AMPK in neutrophils also prevented the dysregulated chemotaxis of neutrophils responsible for sepsisassociated organ damage [229]. Thus, AMPK plays a critical regulator of immunometabolism during sepsis in macrophages as well as in neutrophils and prevents severe organ damage during sepsis via preventing sepsis-associated immunosuppression. However, the metformin treatment proved harmful in systemic fungal infection causing sepsis due to its inhibitory action on mTOR signaling and cytokine production including TNF- $\alpha$ and IL-1 $\beta$ [230]. Thus, the pathogenic cause of sepsis should be kept in mind before targeting AMPK-dependent immunometabolic reprogramming by metformin.
A decrease in genes regulating TCA cycle during sepsis is reported [i.e., isocitrate dehydrogenase (Idh1)] $[215,231,232]$. This causes an accumulation of succinate and citrate in macrophages due to the suppression of the enzymatic activity of isocitrate dehydrogenase (Idh1) [231, 232]. This increased oxidation of succinic acid or succinate in mitochondria by succinate dehydrogenase (SDH) causes an increased production of ROS along with other proinflammatory molecules (i.e., HIF-1 $\alpha$ ) [233]. Dimethyl malonate (DMM) treatment inhibited the succinate oxidation in macrophages and exerted anti-inflammatory effect during sepsis [233]. In addition to impacting innate immune cell metabolism during sepsis, targeting $\mathrm{T}$ cells immunometabolism may also prove beneficial during sepsis. For example, IL-7 signaling is required for the survival and maintenance of normal growth, division, and proliferation of naïve conventional T cells via tonic TCR signaling required for the uptake of glucose [204]. A very low level of systemic/circulating IL-7 is reported in sepsis patients [207]. The treatment of animals suffering from sepsis with recombinant human IL-7 (rhIL-7) increased their survival $[234,235]$. The treatment with IL-7 also exerted an impact on immunometabolism via improving mTOR signaling, GLUT1 surface expression, and glucose uptake by T cells [236]. Two phase II clinical trials focused on rhIL-7 (CYT107) in sepsis are just finished in the USA and France $[237,238]$ and their results are promising [239]. The CYT107 reversed the major loss of $\mathrm{CD}^{+}$and $\mathrm{CD} 8^{+} \mathrm{T}$ cells responsible for sepsis-associated immunosuppression that serves as a hallmark of sepsis and one of the key mechanism related with its high morbidity and mortality.

An increased extracellular lactate level is observed in sepsis patients and this environment proves supportive for regulatory T cells (Tregs) as these cells can maintain their redox balance under this condition and are capable of exerting their immunosuppressive function [240, 241]. Thus, this prolonged survival of Tregs may be responsible for the later immunosuppressive stage of sepsis and targeting specifically Tregs and their immunometabolism at later stages can prove beneficial to patients with immunosuppression [242, 243]. The inhibition of mTORC1 with low-dose combination of a catalytic (BEZ235) plus an allosteric (RAD001) mTOR inhibitor called rapalog in older people is shown to improve their immune function and prevented the development of certain infections that can develop into sepsis [244]. It is well established that along with newborns and children, elderly population is more prone to develop infection and sepsis [74, 245-249]. Thus, in addition to elderly population, mTORC1 inhibition can also be used as an immune enhancing strategy via 
modulating the immunometabolism among patients undergone immunosuppression associated with sepsis or are dealing with immunosuppression even after recovering from sepsis [250]. The cell-specific immunometabolic targeting can be achieved via cell-specific receptors and the use of immunotoxins and magic bullets that can be used to deliver specific enzymatic inhibitor or activator controlling different metabolic pathways of the specific immune cell population during sepsis. This magic bullet-based approach can be a successful therapeutic approach for targeting immunometabolism as it has been used successfully in delivering drugs/toxins inside the cells as part of cancer therapeutics [251, 252]. Future studies are urgently required in the direction to targeting immunometabolism during sepsis.

\section{CONCLUSION}

Immunometabolism is a relatively new branch of immunology with its potential to have great application in diverse diseases varying from cancer to autoimmunity to infectious diseases including sepsis. A well-controlled metabolic pathway is the major requirement for survival, growth, division, and proliferation of immune cells during homeostatic conditions or during various diseases including sepsis. If this metabolic control of immunity is broken as observed during sepsis, it may lead to either death of the immune cells due to their increased apoptosis as observed with conventional $\mathrm{T}$ cells in sepsis [253] or their increased proliferation and pro-inflammatory or immunosuppressive action depending on the cell type and the stage of sepsis. Thus, studying a shift in immunometabolic stage of various immune cells at different stages of sepsis has a great potential to control both over-activation of the immune system or immunosuppression observed during sepsis. This can lead to further develop immunometabolismbased therapeutics targeting sepsis that can be easily delivered inside the specific population of immune cells under therapeutic targeting by using the novel drug delivery systems. The successful completion of two phase trials of II rhIL-7 or CYT107 has shown the importance of cellular immunometabolism during sepsis and its cell-specific targeting to managing the sepsis. Thus, its immunometabolism has a bright future in sepsis research in terms of the development of precision medicine or cellspecific biomarker and as a novel approach for immunebased therapeutics. Future studies in this direction are required urgently to target sepsis as it requires a greater attention for developing therapeutic molecules specifically designed to manage sepsis depending on its severity and immune status of the patient. Targeting the immunometabolic reprograming during sepsis has a great potential to open a new avenue for sepsis research and its therapeutic targeting depending on the immune status and severity of the sepsis.

\section{AUTHOR CONTRIBUTIONS}

The corresponding author generated the idea, gathered the cited literature, and wrote the article.

\section{COMPLIANCE WITH ETHICAL STANDARDS}

Competing Interest. The author declares that he does not have any competing interest.

\section{REFERENCES}

1. Singer, M., C.S. Deutschman, C. Seymour, et al. 2016. The third international consensus definitions for sepsis and septic shock (sepsis-3). Jama 315: 801-810.

2. Angus, D.C., and T. van der Poll. 2013. Severe sepsis and septic shock. New England Journal of Medicine 369: 840-851.

3. Shankar-Hari, M., G.S. Phillips, M.L. Levy, et al. 2016. Developing a new definition and assessing new clinical criteria for septic shock: for the third international consensus definitions for sepsis and septic shock (sepsis-3). Jama 315: 775-787.

4. Marik, P.E., W.T. Linde-Zwirble, E.A. Bittner, J. Sahatjian, and D. Hansell. 2017. Fluid administration in severe sepsis and septic shock, patterns and outcomes: an analysis of a large national database. Intensive Care Medicine 43: 625-632.

5. Rhodes, A., L.E. Evans, W. Alhazzani, M.M. Levy, M. Antonelli, R. Ferrer, A. Kumar, J.E. Sevransky, C.L. Sprung, M.E. Nunnally, B. Rochwerg, G.D. Rubenfeld, D.C. Angus, D. Annane, R.J. Beale, G.J. Bellinghan, G.R. Bernard, J.D. Chiche, C. Coopersmith, D.P. De Backer, C.J. French, S. Fujishima, H. Gerlach, J.L. Hidalgo, S.M. Hollenberg, A.E. Jones, D.R. Karnad, R.M. Kleinpell, Y. Koh, T.C. Lisboa, F.R. Machado, J.J. Marini, J.C. Marshall, J.E. Mazuski, L.A. McIntyre, A.S. McLean, S. Mehta, R.P. Moreno, J. Myburgh, P. Navalesi, O. Nishida, T.M. Osborn, A. Perner, C.M. Plunkett, M. Ranieri, C.A. Schorr, M.A. Seckel, C.W. Seymour, L. Shieh, K.A. Shukri, S.Q. Simpson, M. Singer, B.T. Thompson, S.R. Townsend, T. Van der Poll, J.L. Vincent, W.J. Wiersinga, J.L. Zimmerman, and R.P. Dellinger. 2017. Surviving sepsis campaign: international guidelines for management of sepsis and septic shock: 2016. Intensive Care Medicine 43: 304-377.

6. Taeb, A.M., M.H. Hooper, and P.E. Marik. 2017. Sepsis: current definition, pathophysiology, diagnosis, and management. Nutrition in clinical practice : official publication of the American Society for Parenteral and Enteral Nutrition 32: 296-308. 
7. Vincent, J.L., Y. Sakr, C.L. Sprung, V.M. Ranieri, K. Reinhart, H. Gerlach, R. Moreno, J. Carlet, J.R. Le Gall, and D. Payen. 2006. Sepsis in European intensive care units: results of the SOAP study. Critical Care Medicine 34: 344-353.

8. Fleischmann, C., A. Scherag, N.K. Adhikari, C.S. Hartog, T. Tsaganos, P. Schlattmann, D.C. Angus, and K. Reinhart. 2016a. Assessment of global incidence and mortality of hospital-treated sepsis. Current Estimates and Limitations. American journal of respiratory and critical care medicine 193: 259-272.

9. Fleischmann, C., D.O. Thomas-Rueddel, M. Hartmann, C.S. Hartog, T. Welte, S. Heublein, U. Dennler, and K. Reinhart. 2016b. Hospital incidence and mortality rates of sepsis. Deutsches Arzteblatt international 113: 159-166.

10. Cantey, J.B., Milstone, A.M., 2015. Bloodstream infections: epidemiology and resistance. Clinics in Perinatology 42, 1-16, vii.

11. Mohsen, L., N. Ramy, D. Saied, D. Akmal, N. Salama, M.M. Abdel Haleim, and H. Aly. 2017. Emerging antimicrobial resistance in early and late-onset neonatal sepsis. Antimicrobial Resistance and Infection Control 6: 63.

12. Pradipta, I.S., D.C. Sodik, K. Lestari, I. Parwati, E. Halimah, A. Diantini, and R. Abdulah. 2013. Antibiotic resistance in sepsis patients: evaluation and recommendation of antibiotic use. North American Journal of Medical Sciences 5: 344-352.

13. Esposito, S., G. De Simone, G. Boccia, F. De Caro, and P. Pagliano. 2017. Sepsis and septic shock: new definitions, new diagnostic and therapeutic approaches. Journal of Global Antimicrobial Resistance 10: 204-212.

14. Keener, A.B. 2017. Host with the most: targeting host cells instead of pathogens to fight infectious disease. Nature Medicine 23: 528-531.

15. Al-Khami, A.A., P.C. Rodriguez, and A.C. Ochoa. 2016. Metabolic reprogramming of myeloid-derived suppressor cells (MDSC) in cancer. Oncoimmunology 5: e1200771.

16. Beezhold, K., and C.A. Byersdorfer. 2018. Targeting immunometabolism to improve anti-cancer therapies. Cancer Letters 414: 127135 .

17. Bettencourt, I.A., and J.D. Powell. 2017. Targeting metabolism as a novel therapeutic approach to autoimmunity, inflammation, and transplantation. Journal of immunology (Baltimore, Md. : 1950) 198: 999-1005.

18. McKinney, E.F., and K.G.C. Smith. 2018. Metabolic exhaustion in infection, cancer and autoimmunity. Nature Immunology 19: 213-221.

19. Al-Khami, A.A., P.C. Rodriguez, and A.C. Ochoa. 2017. Energy metabolic pathways control the fate and function of myeloid immune cells. Journal of Leukocyte Biology 102: 369-380.

20. Dühring, S., S. Germerodt, C. Skerka, P. Zipfel, T. Dandekar, and S. Schuster. 2015. Host-pathogen interactions between the human innate immune system and Candida albicans - understanding and modeling defense and evasion strategies. Frontiers in Microbiology 6.

21. Kumar, H., T. Kawai, and S. Akira. 2011. Pathogen recognition by the innate immune system. International Reviews of Immunology 30: $16-34$.

22. van der Poll, T., and S.M. Opal. 2008b. Host-pathogen interactions in sepsis. The Lancet Infectious Diseases 8: 32-43.

23. Kan, B., H.R. Razzaghian, and P.M. Lavoie. 2016. An immunological perspective on neonatal sepsis. Trends in Molecular Medicine 22: 290-302.

24. Kollmann, T.R., O. Levy, R.R. Montgomery, and S. Goriely. 2012. Innate immune function by toll-like receptors: distinct responses in newborns and the elderly. Immunity 37: 771-783.

25. Yost, C.C., M.J. Cody, E.S. Harris, N.L. Thornton, A.M. McInturff, M.L. Martinez, N.B. Chandler, C.K. Rodesch, K.H. Albertine, C.A. Petti, A.S. Weyrich, and G.A. Zimmerman. 2009. Impaired neutrophil extracellular trap (NET) formation: a novel innate immune deficiency of human neonates. Blood 113: 6419-6427.

26. Gomez, C.R., E.D. Boehmer, and E.J. Kovacs. 2005. The aging innate immune system. Current Opinion in Immunology 17: 457-462.

27. Montecino-Rodriguez, E., B. Berent-Maoz, and K. Dorshkind. 2013. Causes, consequences, and reversal of immune system aging. The Journal of Clinical Investigation 123: 958-965.

28. Shaw, A.C., S. Joshi, H. Greenwood, A. Panda, and J.M. Lord. 2010. Aging of the innate immune system. Current Opinion in Immunology 22: 507-513.

29. Solana, R., R. Tarazona, I. Gayoso, O. Lesur, G. Dupuis, and T. Fulop. 2012. Innate immunosenescence: effect of aging on cells and receptors of the innate immune system in humans. Seminars in Immunology 24: 331-341.

30. Kumar, V., and A. Sharma. 2008. Innate immunity in sepsis pathogenesis and its modulation: new immunomodulatory targets revealed. Journal of chemotherapy (Florence, Italy) 20: 672-683.

31. van der Poll, T., and S.M. Opal. 2008a. Host-pathogen interactions in sepsis. The Lancet. Infectious diseases 8: 32-43.

32. van der Poll, T., F.L. van de Veerdonk, B.P. Scicluna, and M.G. Netea. 2017. The immunopathology of sepsis and potential therapeutic targets. Nature Reviews. Immunology 17: 407-420.

33. Weber, G.F., and F.K. Swirski. 2014. Immunopathogenesis of abdominal sepsis. Langenbeck's Archives of Surgery 399: 1-9.

34. Wiersinga, W.J., S.J. Leopold, D.R. Cranendonk, and T. van der Poll. 2014. Host innate immune responses to sepsis. Virulence 5: 36-44.

35. Censoplano, N., C.L. Epting, and B.M. Coates. 2014. The role of the innate immune system in sepsis. Clinical Pediatric Emergency Medicine 15: 169-176.

36. Charchaflieh, J., J. Wei, G. Labaze, Y.J. Hou, B. Babarsh, H. Stutz, H. Lee, S. Worah, and M. Zhang. 2012. The role of complement system in septic shock. Clinical and Developmental Immunology 2012: 8 .

37. Markiewski, M.M., R.A. DeAngelis, and J.D. Lambris. 2008. Complexity of complement activation in sepsis. Journal of Cellular and Molecular Medicine 12: 2245-2254.

38. Al-Soudi, A., M.H. Kaaij, and S.W. Tas. 2017. Endothelial cells: From innocent bystanders to active participants in immune responses. Autoimmunity Reviews 16: 951-962.

39. Bell, E. 2009. Endothelial cells as sentinels. Nature Reviews Immunology 9: 532.

40. Mai, J., A. Virtue, J. Shen, H. Wang, and X.-F. Yang. 2013. An evolving new paradigm: endothelial cells - conditional innate immune cells. Journal of Hematology \& Oncology 6: 61-61.

41. Andonegui, G., H. Zhou, D. Bullard, M.M. Kelly, S.C. Mullaly, B. McDonald, E.M. Long, S.M. Robbins, and P. Kubes. 2009. Mice that exclusively express TLR4 on endothelial cells can efficiently clear a lethal systemic Gram-negative bacterial infection. The Journal of Clinical Investigation 119: 1921-1930.

42. Aird, W.C. 2003. The role of the endothelium in severe sepsis and multiple organ dysfunction syndrome. Blood 101: 3765-3777.

43. Boisrame-Helms, J., H. Kremer, V. Schini-Kerth, and F. Meziani. 2013. Endothelial dysfunction in sepsis. Current Vascular Pharmacology 11: 150-160.

44. Ince, C., P.R. Mayeux, T. Nguyen, H. Gomez, J.A. Kellum, G.A Ospina-Tascón, G. Hernandez, P. Murray, and D. De Backer. 2016. THE ENDOTHELIUM IN SEPSIS, Shock (Augusta, Ga.). 45: 259-270.

45. Opal, S.M., and T. van der Poll. 2015. Endothelial barrier dysfunction in septic shock. Journal of Internal Medicine 277: 277-293.

46. Peters, K., R.E. Unger, J. Brunner, and C.J. Kirkpatrick. 2003. Molecular basis of endothelial dysfunction in sepsis. Cardiovascular Research 60: 49-57. 
47. Vallet, B. 2003. Bench-to-bedside review: endothelial cell dysfunction in severe sepsis: a role in organ dysfunction? Critical Care 7: 130-138.

48. Chaudhry, H., Zhou, J., Zhong, Y.I.N., Ali, M.M., McGuire, F., Nagarkatti, P.S., Nagarkatti, M., 2013. Role of cytokines as a double-edged sword in sepsis. In vivo (Athens, Greece) 27, 669684.

49. Chousterman, B.G., F.K. Swirski, and G.F. Weber. 2017. Cytokine storm and sepsis disease pathogenesis. Seminars in Immunopathology 39: 517-528.

50. Tisoncik, J.R., M.J. Korth, C.P. Simmons, J. Farrar, T.R. Martin, and M.G. Katze. 2012. Into the eye of the cytokine storm. Microbiology and Molecular Biology Reviews 76: 16-32.

51. Gogos, C.A., E. Drosou, H.P. Bassaris, and A. Skoutelis. 2000. Pro- versus anti-inflammatory cytokine profile in patients with severe sepsis: a marker for prognosis and future therapeutic options. The Journal of Infectious Diseases 181: 176-180.

52. Schulte, W., J. Bernhagen, and R. Bucala. 2013. Cytokines in sepsis: potent immunoregulators and potential therapeutic targets-an updated view. Mediators of Inflammation 2013: 16.

53. Wang, D.-W., N. Dong, Y. Wu, X.-M. Zhu, C.-T. Wang, and Y.-M. Yao. 2016b. Interleukin-37 enhances the suppressive activity of naturally occurring CD4+CD25+ regulatory T cells. Scientific Reports 6: 38955.

54. Yan, J., A. Mitra, J. Hu, J.J. Cutrera, X. Xia, T. Doetschman, M. Gagea, L. Mishra, and S. Li. 2016. IL-30 (IL27p28) alleviates sepsis via modulation of cytokine profiles produced by NKT cells. Journal of Hepatology 64: 1128-1136.

55. Gerlach, H., 2016. Agents to reduce cytokine storm [version 1; referees: 3 approved].

56. Darenberg, J., N. Ihendyane, J. Sjolin, E. Aufwerber, S. Haidl, P. Follin, J. Andersson, and A. Norrby-Teglund. 2003. Intravenous immunoglobulin G therapy in streptococcal toxic shock syndrome: a European randomized, double-blind, placebo-controlled trial. Clinical infectious diseases : an official publication of the Infectious Diseases Society of America 37: 333-340.

57. Shah, S.S., M. Hall, R. Srivastava, A. Subramony, and J.E. Levin. 2009. Intravenous immunoglobulin in children with streptococcal toxic shock syndrome. Clinical infectious diseases : an official publication of the Infectious Diseases Society of America 49: 1369-1376.

58. Valiquette, L., D.E. Low, and A.J. McGeer. 2009. Assessing the impact of intravenous immunoglobulin in the management of streptococcal toxic shock syndrome: a noble but difficult quest. Clinical infectious diseases : an official publication of the Infectious Diseases Society of America 49: 1377-1379.

59. Marshall, J.C. 2014. Why have clinical trials in sepsis failed? Trends in Molecular Medicine 20: 195-203.

60. Opal, S.M., P.F. Laterre, B. Francois, S.P. LaRosa, D.C. Angus, J.P Mira, X. Wittebole, T. Dugernier, D. Perrotin, M. Tidswell, L. Jauregui, K. Krell, J. Pachl, T. Takahashi, C. Peckelsen, E. Cordasco, C.S. Chang, S. Oeyen, N. Aikawa, T. Maruyama, R. Schein, A.C. Kalil, M. Van Nuffelen, M. Lynn, D.P. Rossignol, J. Gogate, M.B. Roberts, J.L. Wheeler, and J.L. Vincent. 2013. Effect of eritoran, an antagonist of MD2-TLR4, on mortality in patients with severe sepsis: the ACCESS randomized trial. Jama 309: 1154-1162.

61. Hosac, A.M., 2002. Drotrecogin alfa (activated): the first FDAapproved treatment for severe sepsis. Proceedings (Baylor University. Medical center) $15,224-227$.

62. Ranieri, V.M., B.T. Thompson, P.S. Barie, J.-F. Dhainaut, I.S. Douglas, S. Finfer, B. Gårdlund, J.C. Marshall, A. Rhodes, A. Artigas, D. Payen, J. Tenhunen, H.R. Al-Khalidi, V. Thompson,
J. Janes, W.L. Macias, B. Vangerow, and M.D. Williams. 2012. Drotrecogin alfa (activated) in adults with septic shock. New England Journal of Medicine 366: 2055-2064.

63. Botero, JSH., Pérez, MCF., 2012. in: Azevedo, L. (Ed.), Sepsis - an ongoing and significant challenge. InTech, Rijeka, p. Ch. 01.

64. Geroulanos, S., and E.T. Douka. 2006. Historical perspective of the word "sepsis". Intensive Care Medicine 32: 2077.

65. Jamme, M., F. Daviaud, J. Charpentier, N. Marin, M. Thy, Y. Hourmant, J.P. Mira, and F. Pene. 2017. Time course of septic shock in immunocompromised and nonimmunocompromised patients. Critical Care Medicine 45: 2031-2039.

66. Tolsma, V., C. Schwebel, E. Azoulay, M. Darmon, B. Souweine, A. Vesin, D. Goldgran-Toledano, M. Lugosi, S. Jamali, C. Cheval, C. Adrie, H. Kallel, A. Descorps-Declere, M. Garrouste-Orgeas, L. Bouadma, and J.F. Timsit. 2014. Sepsis severe or septic shock: outcome according to immune status and immunodeficiency profile. Chest 146: 1205-1213.

67. Man, K., V.I. Kutyavin, and A. Chawla. 2017. Tissue immunometabolism: development, physiology, and pathobiology. Cell Metabolism 25: 11-26.

68. Gaber, T., C. Strehl, and F. Buttgereit. 2017. Metabolic regulation of inflammation. Nature reviews. Rheumatology 13: 267-279.

69. Hotamisligil, G.S. 2017. Inflammation, metaflammation and immunometabolic disorders. Nature 542: 177-185.

70. O'Neill, L.A., R.J. Kishton, and J. Rathmell. 2016. A guide to immunometabolism for immunologists. Nature Reviews. Immunology 16: $553-565$.

71. Stienstra, R., R.T. Netea-Maier, N.P. Riksen, L.A.B. Joosten, and M.G. Netea. 2017. Specific and complex reprogramming of cellular metabolism in myeloid cells during innate immune responses. Cell Metabolism 26: 142-156.

72. Evangelatos, N., Bauer, P., Reumann, M., Satyamoorthy, K., Lehrach, H., Brand, A., 2018. Metabolomics in sepsis and its impact on public health. Public health genomics.

73. Everts, B. 2018. Metabolomics in immunology research. Methods in molecular biology (Clifton, N.J.) 1730: 29-42.

74. Nasa, P., D. Juneja, and O. Singh. 2012. Severe sepsis and septic shock in the elderly: an overview. World journal of critical care medicine 1: 23-30.

75. Bantug, G.R., L. Galluzzi, G. Kroemer, and C. Hess. 2018. The spectrum of T cell metabolism in health and disease. Nature Reviews. Immunology 18: 19-34.

76. Eelen, G., P. de Zeeuw, M. Simons, and P. Carmeliet. 2015. Endothelial cell metabolism in normal and diseased vasculature. Circulation Research 116: 1231-1244.

77. Gleeson, L.E., and F.J. Sheedy. 2016. Metabolic reprogramming \& inflammation: fuelling the host response to pathogens. Seminars in Immunology 28: 450-468.

78. Pircher, A., L. Treps, N. Bodrug, and P. Carmeliet. 2016. Endothelial cell metabolism: a novel player in atherosclerosis? Basic principles and therapeutic opportunities. Atherosclerosis 253: $247-$ 257.

79. Rohlenova, K., K. Veys, I. Miranda-Santos, K. De Bock, and P. Carmeliet. 2018. Endothelial cell metabolism in health and disease. Trends in Cell Biology 28: 224-236.

80. O'Neill, L.A., and E.J. Pearce. 2016. Immunometabolism governs dendritic cell and macrophage function. The Journal of Experimental Medicine 213: 15-23.

81. Wang, A., S.C. Huen, H.H. Luan, S. Yu, C. Zhang, J.D. Gallezot, C.J. Booth, and R. Medzhitov. 2016a. Opposing effects of fasting metabolism on tissue tolerance in bacterial and viral inflammation. Cell 166: 1512-1525.e1512. 
82. Gardiner, C.M., and D.K. Finlay. 2017. What fuels natural killers? Metabolism and NK cell responses. Frontiers in Immunology 8: 367.

83. Mills, E.L., B. Kelly, and L.A.J. O'Neill. 2017. Mitochondria are the powerhouses of immunity. Nature Immunology 18: 488-498.

84. Monlun, M., C. Hyernard, P. Blanco, L. Lartigue, and B. Faustin. 2017. Mitochondria as molecular platforms integrating multiple innate immune signalings. Journal of Molecular Biology 429: 113.

85. Dale, D.C., L. Boxer, and W.C. Liles. 2008. The phagocytes: neutrophils and monocytes. Blood 112: 935-945.

86. Del Fresno, C., and A. Hidalgo. 2017. Neutrophils acROSs the enemy lines. Immunity 46: 335-337.

87. Kumar, V., and A. Sharma. 2010. Neutrophils: Cinderella of innate immune system. International Immunopharmacology 10: 13251334.

88. Mócsai, A. 2013. Diverse novel functions of neutrophils in immunity, inflammation, and beyond. The Journal of Experimental Medicine 210: 1283-1299.

89. Nicolas-Avila, J.A., J.M. Adrover, and A. Hidalgo. 2017. Neutrophils in homeostasis, immunity, and cancer. Immunity 46: 15-28.

90. de Kleijn, S., M. Kox, I.E. Sama, J. Pillay, A. van Diepen, M.A. Huijnen, J.G. van der Hoeven, G. Ferwerda, P.W.M. Hermans, and P. Pickkers. 2012. Transcriptome kinetics of circulating neutrophils during human experimental endotoxemia. PLoS One 7: e38255.

91. Moulding, D.A., J.A. Quayle, C.A. Hart, and S.W. Edwards. 1998. Mcl-1 expression in human neutrophils: regulation by cytokines and correlation with cell survival. Blood 92: 2495-2502.

92. Shen, X.F., K. Cao, J.P. Jiang, W.X. Guan, and J.F. Du. 2017. Neutrophil dysregulation during sepsis: an overview and update. Journal of Cellular and Molecular Medicine 21: 1687-1697.

93. Sônego, F., F.V.S. Castanheira, R.G. Ferreira, A. Kanashiro, C.A.V.G. Leite, D.C. Nascimento, D.F. Colón, V.F. Borges, J.C. Alves-Filho, and F.Q. Cunha. 2016. Paradoxical roles of the neutrophil in sepsis: protective and deleterious. Frontiers in Immunology 7: 155.

94. Weinmann, P., P. Gaehtgens, and B. Walzog. 1999. Bcl-Xl- and Bax-alpha-mediated regulation of apoptosis of human neutrophils via caspase-3. Blood 93: 3106-3115.

95. Jia, S.H., J. Parodo, E. Charbonney, J.L.Y. Tsang, S.Y. Jia, O.D. Rotstein, A. Kapus, and J.C. Marshall. 2014. Activated neutrophils induce epithelial cell apoptosis through oxidant-dependent tyrosine dephosphorylation of caspase-8. The American Journal of Pathology 184: 1030-1040.

96. Wang, J.F., J.B. Li, Y.J. Zhao, W.J. Yi, J.J. Bian, X.J. Wan, K.M. Zhu, and X.M. Deng. 2015. Up-regulation of programmed cell death 1 ligand 1 on neutrophils may be involved in sepsis-induced immunosuppression: an animal study and a prospective casecontrol study. Anesthesiology 122: 852-863.

97. Arasanz, H., M. Gato-Cañas, M. Zuazo, M. Ibañez-Vea, K. Breckpot, G. Kochan, and D. Escors. 2017. PD1 signal transduction pathways in T cells. Oncotarget 8: 51936-51945.

98. Riley, J.L. 2009. PD-1 signaling in primary T cells. Immunological Reviews 229: 114-125.

99. Chemnitz, J.M., R.V. Parry, K.E. Nichols, C.H. June, and J.L. Riley. 2004. SHP-1 and SHP-2 associate with immunoreceptor tyrosine-based switch motif of programmed death 1 upon primary human $\mathrm{T}$ cell stimulation, but only receptor ligation prevents T cell activation. Journal of immunology (Baltimore, Md. : 1950) 173: 945-954.

100. Hui, E., J. Cheung, J. Zhu, X. Su, M.J. Taylor, H.A. Wallweber, D.K. Sasmal, J. Huang, J.M. Kim, I. Mellman, and R.D. Vale. 2017. T cell costimulatory receptor $\mathrm{CD} 28$ is a primary target for
PD-1-mediated inhibition. Science (New York, N.Y.) 355: 14281433.

101. Lorenz, U. 2009. SHP-1 and SHP-2 in T cells: two phosphatases functioning at many levels. Immunological Reviews 228: 342-359.

102. Sheppard, K.A., L.J. Fitz, J.M. Lee, C. Benander, J.A. George, J. Wooters, Y. Qiu, J.M. Jussif, L.L. Carter, C.R. Wood, and D. Chaudhary. 2004. PD-1 inhibits T-cell receptor induced phosphorylation of the ZAP70/CD3zeta signalosome and downstream signaling to PKCtheta. FEBS Letters 574: 37-41.

103. Patsoukis, N., L. Li, D. Sari, V. Petkova, and V.A. Boussiotis. 2013. PD-1 increases PTEN phosphatase activity while decreasing PTEN protein stability by inhibiting casein kinase 2. Molecular and Cellular Biology 33: 3091-3098.

104. Patsoukis, N., K. Bardhan, P. Chatterjee, D. Sari, B. Liu, L.N. Bell, E.D. Karoly, G.J. Freeman, V. Petkova, P. Seth, L. Li, and V.A. Boussiotis. 2015. PD-1 alters T-cell metabolic reprogramming by inhibiting glycolysis and promoting lipolysis and fatty acid oxidation. Nature Communications 6: 6692.

105. Wong, H.R., R.J. Freishtat, M. Monaco, K. Odoms, and T.P. Shanley. 2010. Leukocyte subset-derived genomewide expression profiles in pediatric septic shock. Pediatric critical care medicine : a journal of the Society of Critical Care Medicine and the World Federation of Pediatric Intensive and Critical Care Societies 11: 349-355.

106. Fox, E.D., D.S. Heffernan, W.G. Cioffi, and J.S. Reichner. 2013. Neutrophils from critically ill septic patients mediate profound loss of endothelial barrier integrity. Critical care (London, England) 17: R226.

107. Rimmele, T., Payen, D., Cantaluppi, V., Marshall, J., Gomez, H., Gomez, A., Murray, P., Kellum, J.A., 2016. IMMUNE CELL PHENOTYPE AND FUNCTION IN SEPSIS. Shock (Augusta, Ga.) 45, 282-291.

108. Hoesel, L.M., T.A. Neff, S.B. Neff, J.G. Younger, E.W. Olle, H. Gao, M.J. Pianko, K.D. Bernacki, J.V. Sarma, and P.A. Ward. 2005. Harmful and protective roles of neutrophils in sepsis. Shock (Augusta, Ga.) 24: 40-47.

109. Alves-Filho, J.C., F. Spiller, and F.Q. Cunha. 2010. Neutrophil paralysis in sepsis. Shock (Augusta, Ga.) 34 (Suppl 1): 15-21.

110. Bermejo-Martín, J.F., E. Tamayo, G. Ruiz, D. Andaluz-Ojeda, R. Herrán-Monge, A. Muriel-Bombín, M. Fe Muñoz, M. HerediaRodríguez, R. Citores, J.I. Gómez-Herreras, and J. Blanco. 2014. Circulating neutrophil counts and mortality in septic shock. Critical Care 18: 407-407.

111. Mare, T.A., D.F. Treacher, M. Shankar-Hari, R. Beale, S.M. Lewis, D.J. Chambers, and K.A. Brown. 2015. The diagnostic and prognostic significance of monitoring blood levels of immature neutrophils in patients with systemic inflammation. Critical care (London, England) 19: -57.

112. Demaret, J., F. Venet, A. Friggeri, M.A. Cazalis, J. Plassais, L. Jallades, C. Malcus, F. Poitevin-Later, J. Textoris, A. Lepape, and G. Monneret. 2015. Marked alterations of neutrophil functions during sepsis-induced immunosuppression. Journal of Leukocyte Biology 98: 1081-1090.

113. Brown, K.A., S.D. Brain, J.D. Pearson, J.D. Edgeworth, S.M. Lewis, and D.F. Treacher. 2006. Neutrophils in development of multiple organ failure in sepsis. Lancet (London, England) 368: 157-169.

114. Meyer-Hoffert, U., and O. Wiedow. 2011. Neutrophil serine proteases: mediators of innate immune responses. Current Opinion in Hematology 18: 19-24.

115. Delabranche, X., L. Stiel, F. Severac, A.C. Galoisy, L. Mauvieux, F. Zobairi, T. Lavigne, F. Toti, E. Angles-Cano, F. Meziani, and J. Boisrame-Helms. 2017. Evidence of netosis in septic shock- 
induced disseminated intravascular coagulation. Shock (Augusta, Ga.) 47: 313-317.

116. McDonald, B., R.P. Davis, S.J. Kim, M. Tse, C.T. Esmon, E. Kolaczkowska, and C.N. Jenne. 2017. Platelets and neutrophil extracellular traps collaborate to promote intravascular coagulation during sepsis in mice. Blood 129: 1357-1367.

117. Evans, W.H., Karnovsky, M.L., 1962. The biochemical basis of phagocytosis. IV. Some aspects of carbohydrate metabolism during phagocytosis. Biochemistry 1, 159-166.

118. Lodhi, I.J., X. Wei, L. Yin, C. Feng, S. Adak, G. Abou-Ezzi, F.F. Hsu, D.C. Link, and C.F. Semenkovich. 2015. Peroxisomal lipid synthesis regulates inflammation by sustaining neutrophil membrane phospholipid composition and viability. Cell Metabolism 21: 51-64.

119. Sbarra, A.J., and M.L. Karnovsky. 1959. The biochemical basis of phagocytosis. I. Metabolic changes during the ingestion of particles by polymorphonuclear leukocytes. The Journal of biological chemistry 234: $1355-1362$.

120. Biswas, S.K. 2015. Metabolic reprogramming of immune cells in cancer progression. Immunity 43: 435-449.

121. Borregaard, N., and T. Herlin. 1982. Energy metabolism of human neutrophils during phagocytosis. The Journal of Clinical Investigation 70: 550-557.

122. Jun, H.S., D.A. Weinstein, Y.M. Lee, B.C. Mansfield, and J.Y Chou. 2014. Molecular mechanisms of neutrophil dysfunction in glycogen storage disease type Ib. Blood 123: 2843-2853.

123. Guthrie, L.A., L.C. McPhail, P.M. Henson, and R.B. Johnston Jr. 1984. Priming of neutrophils for enhanced release of oxygen metabolites by bacterial lipopolysaccharide. Evidence for increased activity of the superoxide-producing enzyme. The Journal of experimental medicine 160: 1656-1671.

124. Winterbourn, C.C., A.J. Kettle, and M.B. Hampton. 2016. Reactive oxygen species and neutrophil function. Annual Review of Biochemistry 85: 765-792.

125. Azevedo, E.P., N.C. Rochael, A.B. Guimaraes-Costa, T.S. de Souza-Vieira, J. Ganilho, E.M. Saraiva, F.L. Palhano, and D. Foguel. 2015. A metabolic shift toward pentose phosphate pathway is necessary for amyloid fibril- and phorbol 12-myristate 13acetate-induced neutrophil extracellular trap (NET) formation. The Journal of Biological Chemistry 290: 22174-22183.

126. Park, D.W., and J.W. Zmijewski. 2017. Mitochondrial dysfunction and immune cell metabolism in sepsis. Infection \& chemotherapy 49: $10-21$.

127. Rodriguez-Espinosa, O., O. Rojas-Espinosa, M.M. MorenoAltamirano, E.O. Lopez-Villegas, and F.J. Sanchez-Garcia. 2015. Metabolic requirements for neutrophil extracellular traps formation. Immunology 145: 213-224.

128. Maianski, N.A., J. Geissler, S.M. Srinivasula, E.S. Alnemri, D. Roos, and T.W. Kuijpers. 2004. Functional characterization of mitochondria in neutrophils: a role restricted to apoptosis. Cell Death and Differentiation 11: 143-153.

129. Pearce, Erika L., and Edward J. Pearce. 2013. Metabolic pathways in immune cell activation and quiescence. Immunity 38: 633-643.

130. Fossati, G., D.A. Moulding, D.G. Spiller, R.J. Moots, M.R. White, and S.W. Edwards. 2003. The mitochondrial network of human neutrophils: role in chemotaxis, phagocytosis, respiratory burst activation, and commitment to apoptosis. Journal of immunology (Baltimore, Md. : 1950) 170: 1964-1972.

131. van Raam, B.J., W. Sluiter, E. de Wit, D. Roos, A.J. Verhoeven, and T.W. Kuijpers. 2008. Mitochondrial membrane potential in human neutrophils is maintained by complex III activity in the absence of supercomplex organisation. PLoS One 3: e2013.
132. Remijsen, Q., T.W. Kuijpers, E. Wirawan, S. Lippens, P. Vandenabeele, and T. Vanden Berghe. 2011. Dying for a cause: NETosis, mechanisms behind an antimicrobial cell death modality. Cell Death and Differentiation 18: 581.

133. Lu, H., R.A. Forbes, and A. Verma. 2002. Hypoxia-inducible factor 1 activation by aerobic glycolysis implicates the Warburg effect in carcinogenesis. The Journal of Biological Chemistry 277: 2311123115.

134. Sun, Q., X. Chen, J. Ma, H. Peng, F. Wang, X. Zha, Y. Wang, Y. Jing, H. Yang, R. Chen, L. Chang, Y. Zhang, J. Goto, H. Onda, T. Chen, M.R. Wang, Y. Lu, H. You, D. Kwiatkowski, and H. Zhang. 2011. Mammalian target of rapamycin up-regulation of pyruvate kinase isoenzyme type M2 is critical for aerobic glycolysis and tumor growth. Proceedings of the National Academy of Sciences of the United States of America 108: 4129-4134.

135. Cramer, T., Y. Yamanishi, B.E. Clausen, I. Forster, R. Pawlinski, N. Mackman, V.H. Haase, R. Jaenisch, M. Corr, V. Nizet, G.S Firestein, H.P. Gerber, N. Ferrara, and R.S. Johnson. 2003. HIF1alpha is essential for myeloid cell-mediated inflammation. Cell 112: 645-657.

136. Halligan, D.N., S.J. Murphy, and C.T. Taylor. 2016. The hypoxiainducible factor (HIF) couples immunity with metabolism. Seminars in Immunology 28: 469-477.

137. Semenza, G.L., P.H. Roth, H.M. Fang, and G.L. Wang. 1994. Transcriptional regulation of genes encoding glycolytic enzymes by hypoxia-inducible factor 1. The Journal of Biological Chemistry 269: 23757-23763.

138. Peyssonnaux, C., V. Datta, T. Cramer, A. Doedens, E.A. Theodorakis, R.L. Gallo, N. Hurtado-Ziola, V. Nizet, and R.S. Johnson. 2005. HIF-1alpha expression regulates the bactericidal capacity of phagocytes. The Journal of Clinical Investigation 115: 1806-1815.

139. Cheng, S.C., J. Quintin, R.A. Cramer, K.M. Shepardson, S. Saeed, V. Kumar, E.J. Giamarellos-Bourboulis, J.H. Martens, N.A. Rao, A. Aghajanirefah, G.R. Manjeri, Y. Li, D.C. Ifrim, R.J. Arts, B.M. van der Veer, P.M. Deen, C. Logie, L.A. O'Neill, P. Willems, F.L. van de Veerdonk, J.W. van der Meer, A. Ng, L.A. Joosten, C. Wijmenga, H.G. Stunnenberg, R.J. Xavier, and M.G. Netea. 2014. mTOR- and HIF-1 alpha-mediated aerobic glycolysis as metabolic basis for trained immunity. Science (New York, N.Y.) 345: 1250684.

140. Delano, M.J., and P.A. Ward. 2016. The immune system's role in sepsis progression, resolution, and long-term outcome. Immunological Reviews 274: 330-353.

141. Howell, J.J., and B.D. Manning. 2011. mTOR couples cellular nutrient sensing to organismal metabolic homeostasis. Trends in Endocrinology and Metabolism: TEM 22: 94-102.

142. Krawczyk, C.M., T. Holowka, J. Sun, J. Blagih, E. Amiel, R.J. DeBerardinis, J.R. Cross, E. Jung, C.B. Thompson, R.G. Jones, and E.J. Pearce. 2010. Toll-like receptor-induced changes in glycolytic metabolism regulate dendritic cell activation. Blood 115: $4742-4749$

143. Liu, L., S. Das, W. Losert, and C.A. Parent. 2010. mTORC2 REGULATES NEUTROPHIL CHEMOTAXIS IN A cAMPAND RhoA-DEPENDENT FASHION. Developmental Cell 19: 845-857.

144. Itakura, A., and O.J.T. McCarty. 2013. Pivotal role for the mTOR pathway in the formation of neutrophil extracellular traps via regulation of autophagy. American Journal of Physiology - Cell Physiology 305: C348-C354.

145. McInturff, A.M., M.J. Cody, E.A. Elliott, J.W. Glenn, J.W. Rowley, M.T. Rondina, and C.C. Yost. 2012. Mammalian target of rapamycin regulates neutrophil extracellular trap formation via 
induction of hypoxia-inducible factor 1 alpha. Blood 120: 31183125.

146. Chen, F., A. Cao, S. Yao, H.L. Evans-Marin, H. Liu, W. Wu, E.D. Carlsen, S.M. Dann, L. Soong, J. Sun, Q. Zhao, and Y. Cong. 2016. mTOR mediates IL-23 induction of neutrophil IL-17 and IL-22 production. Journal of immunology (Baltimore, Md. : 1950) 196: 4390-4399.

147. Kumar, V. 2013. Adenosine as an endogenous immunoregulator in cancer pathogenesis: where to go? Purinergic Signalling 9: 145-165.

148. Kwak, Y., H.E. Kim, and S.G. Park. 2015. Insights into myeloidderived suppressor cells in inflammatory diseases. Archivum Immunologiae et Therapiae Experimentalis (Warsz) 63: 269-285.

149. Ost, M., Singh, A., Peschel, A., Mehling, R., Rieber, N., Hartl, D., 2016. Myeloid-derived suppressor cells in bacterial infections. Frontiers in Cellular and Infection Microbiology 6.

150. Ostrand-Rosenberg, S., and P. Sinha. 2009. Myeloid-derived suppressor cells: linking inflammation and cancer. The Journal of Immunology 182: 4499-4506.

151. Gabrilovich, D.I., and S. Nagaraj. 2009. Myeloid-derived suppressor cells as regulators of the immune system. Nature Reviews. Immunology 9: 162-174.

152. Brudecki, L., D.A. Ferguson, C.E. McCall, and M. El Gazzar. 2012. Myeloid-derived suppressor cells evolve during sepsis and can enhance or attenuate the systemic inflammatory response. Infection and Immunity 80: 2026-2034.

153. Delano, M.J., P.O. Scumpia, J.S. Weinstein, D. Coco, S. Nagaraj, K.M. Kelly-Scumpia, K.A. O'Malley, J.L. Wynn, S. Antonenko, S.Z. Al-Quran, R. Swan, C.S. Chung, M.A. Atkinson, R. Ramphal, D.I. Gabrilovich, W.H. Reeves, A. Ayala, J. Phillips, D. Laface, P.G. Heyworth, M. Clare-Salzler, and L.L. Moldawer. 2007. MyD88-dependent expansion of an immature GR-1(+)CD11b(+) population induces $\mathrm{T}$ cell suppression and $\mathrm{Th} 2$ polarization in sepsis. The Journal of Experimental Medicine 204: 1463-1474.

154. Derive, M., Y. Bouazza, C. Alauzet, and S. Gibot. 2012. Myeloidderived suppressor cells control microbial sepsis. Intensive Care Medicine 38: 1040-1049.

155. Cuenca, A.G., and L.L. Moldawer. 2012. Myeloid-derived suppressor cells in sepsis: friend or foe? Intensive Care Medicine 38: 928-930

156. Lai, D., C. Qin, and Q. Shu. 2014. Myeloid-derived suppressor cells in sepsis. BioMed Research International 2014: 8.

157. Uhel, F., I. Azzaoui, M. Gregoire, C. Pangault, J. Dulong, J.M. Tadie, A. Gacouin, C. Camus, L. Cynober, T. Fest, Y. Le Tulzo, M. Roussel, and K. Tarte. 2017. Early expansion of circulating granulocytic myeloid-derived suppressor cells predicts development of nosocomial infections in patients with sepsis. American Journal of Respiratory and Critical Care Medicine 196: 315-327.

158. Goh, C., S. Narayanan, and Y.S. Hahn. 2013. Myeloid-derived suppressor cells: the dark knight or the joker in viral infections? Immunological Reviews 255: 210-221.

159. Haile, L.A., R. von Wasielewski, J. Gamrekelashvili, C. Kruger, O. Bachmann, A.M. Westendorf, J. Buer, R. Liblau, M.P. Manns, F. Korangy, and T.F. Greten. 2008. Myeloid-derived suppressor cells in inflammatory bowel disease: a new immunoregulatory pathway. Gastroenterology 135: 871-881 881.e871-875.

160. Kim, Y.-J., S.-Y. Chang, and H.-J. Ko. 2015. Myeloid-derived suppressor cells in inflammatory bowel disease. Intestinal Research 13: 105-111.

161. Qin, A., W. Cai, T. Pan, K. Wu, Q. Yang, N. Wang, Y. Liu, D. Yan, F. Hu, P. Guo, X. Chen, L. Chen, H. Zhang, X. Tang, and J. Zhou. 2013. Expansion of monocytic myeloid-derived suppressor cells dampens T cell function in HIV-1-seropositive individuals. Journal of Virology 87: 1477-1490.
162. Tacke, R.S., H.C. Lee, C. Goh, J. Courtney, S.J. Polyak, H.R. Rosen, and Y.S. Hahn. 2012. Myeloid suppressor cells induced by hepatitis $\mathrm{C}$ virus suppress T-cell responses through the production of reactive oxygen species. Hepatology (Baltimore, Md.) 55: 343-353.

163. Bunt, S.K., P. Sinha, V.K. Clements, J. Leips, and S. OstrandRosenberg. 2006. Inflammation induces myeloid-derived suppressor cells that facilitate tumor progression. Journal of immunology (Baltimore, Md. : 1950) 176: 284-290.

164. Porta, C., Marino, A., Consonni, F.M., Bleve, A., Mola, S., Storto, M., Riboldi, E., Sica, A., 2018. Metabolic influence on the differentiation of suppressive myeloid cells in cancer. Carcinogenesis, bgy088-bgy088.

165. Tu, S., G. Bhagat, G. Cui, S. Takaishi, E.A. Kurt-Jones, B. Rickman, K.S. Betz, M. Penz-Oesterreicher, O. Bjorkdahl, J.G. Fox, and T.C. Wang. 2008. Overexpression of interleukin-1beta induces gastric inflammation and cancer and mobilizes myeloidderived suppressor cells in mice. Cancer Cell 14: 408-419.

166. Hossain, F., A.A. Al-Khami, D. Wyczechowska, C. Hernandez, L. Zheng, K. Reiss, L.D. Valle, J. Trillo-Tinoco, T. Maj, W. Zou, P.C. Rodriguez, and A.C. Ochoa. 2015. Inhibition of fatty acid oxidation modulates immunosuppressive functions of myeloid-derived suppressor cells and enhances cancer therapies. Cancer Immunology Research 3: 1236-1247.

167. Gabrilovich, D.I., S. Ostrand-Rosenberg, and V. Bronte. 2012. Coordinated regulation of myeloid cells by tumours. Nature Reviews. Immunology 12: 253-268.

168. Cai, T.-T., S.-B. Ye, Y.-N. Liu, J. He, Q.-Y. Chen, H.-Q. Mai, C.-X. Zhang, J. Cui, X.-S. Zhang, P. Busson, Y.-X. Zeng, and J. Li. 2017. LMP1-mediated glycolysis induces myeloid-derived suppressor cell expansion in nasopharyngeal carcinoma. PLoS Pathogens 13: e1006503.

169. Hammami, I., J. Chen, F. Murschel, V. Bronte, G. De Crescenzo, and M. Jolicoeur. 2012. Immunosuppressive activity enhances central carbon metabolism and bioenergetics in myeloid-derived suppressor cells in vitro models. BMC Cell Biology 13: 18.

170. Corzo, C.A., T. Condamine, L. Lu, M.J. Cotter, J.I. Youn, P. Cheng, H.I. Cho, E. Celis, D.G. Quiceno, T. Padhya, T.V. McCaffrey, J.C. McCaffrey, and D.I. Gabrilovich. 2010. HIF-1 alpha regulates function and differentiation of myeloid-derived suppressor cells in the tumor microenvironment. The Journal of Experimental Medicine 207: 2439-2453.

171. Noman, M.Z., G. Desantis, B. Janji, M. Hasmim, S. Karray, P. Dessen, V. Bronte, and S. Chouaib. 2014. PD-L1 is a novel direct target of HIF-1alpha, and its blockade under hypoxia enhanced MDSC-mediated T cell activation. The Journal of Experimental Medicine 211: 781-790.

172. Marcu, R., Y.J. Choi, J. Xue, C.L. Fortin, Y. Wang, R.J. Nagao, J. Xu, J.W. MacDonald, T.K. Bammler, C.E. Murry, K. Muczynski, K.R. Stevens, J. Himmelfarb, S.M. Schwartz, and Y. Zheng. 2018. Human organ-specific endothelial cell heterogeneity. iScience 4: $20-35$.

173. Ivanov, A.N., I.A. Norkin, D.M. Puchin'ian, V. Shirokov, and O. Zhdanova. 2014. Endothelial cell adhesion molecules. Uspekhi Fiziologicheskikh Nauk 45: 34-49.

174. Ye, X., J. Ding, X. Zhou, G. Chen, and S.F. Liu. 2008. Divergent roles of endothelial NF- $\mathrm{kB}$ in multiple organ injury and bacterial clearance in mouse models of sepsis. The Journal of Experimental Medicine 205: 1303-1315.

175. Kim, B., C. Jang, H. Dharaneeswaran, J. Li, M. Bhide, S. Yang, K. $\mathrm{Li}$, and Z. Arany. 2018. Endothelial pyruvate kinase M2 maintains vascular integrity. The Journal of Clinical Investigation 128: 4543 4556. 
176. Parikh, S.M. 2013. Dysregulation of the angiopoietin-Tie-2 axis in sepsis and ARDS. Virulence 4: 517-524.

177. Parikh, S.M. 2017. The angiopoietin-Tie2 signaling axis in systemic inflammation. Journal of the American Society of Nephrology 28: 1973-1982.

178. Scholz, A., K.H. Plate, and Y. Reiss. 2015. Angiopoietin-2: a multifaceted cytokine that functions in both angiogenesis and inflammation. Annals of the New York Academy of Sciences 1347: 45-51.

179. De Bock, K., M. Georgiadou, S. Schoors, A. Kuchnio, B.W. Wong, A.R. Cantelmo, A. Quaegebeur, B. Ghesquiere, S. Cauwenberghs, G. Eelen, L.K. Phng, I. Betz, B. Tembuyser, K. Brepoels, J. Welti, I. Geudens, I. Segura, B. Cruys, F. Bifari, I. Decimo, R. Blanco, S. Wyns, J. Vangindertael, S. Rocha, R.T. Collins, S. Munck, D. Daelemans, H. Imamura, R. Devlieger, M. Rider, P.P. Van Veldhoven, F. Schuit, R. Bartrons, J. Hofkens, P. Fraisl, S. Telang, R.J. Deberardinis, L. Schoonjans, S. Vinckier, J. Chesney, H. Gerhardt, M. Dewerchin, and P. Carmeliet. 2013. Role of PFKFB3-driven glycolysis in vessel sprouting. Cell 154: 651-663.

180. DeBerardinis, R.J., J.J. Lum, G. Hatzivassiliou, and C.B. Thompson. 2008. The biology of cancer: metabolic reprogramming fuels cell growth and proliferation. Cell Metabolism 7: 11-20.

181. Pavlova, N.N., and C.B. Thompson. 2016. The emerging hallmarks of cancer metabolism. Cell Metabolism 23: 27-47.

182. Wu, G., T.E. Haynes, H. Li, and C.J. Meininger. 2000. Glutamine metabolism in endothelial cells: ornithine synthesis from glutamine via pyrroline-5-carboxylate synthase. Comparative biochemistry and physiology. Part A, Molecular \& integrative physiology 126: $115-123$.

183. Leighton, B., R. Curi, A. Hussein, and E.A. Newsholme. 1987. Maximum activities of some key enzymes of glycolysis, glutaminolysis, Krebs cycle and fatty acid utilization in bovine pulmonary endothelial cells. FEBS Letters 225: 93-96.

184. Unterluggauer, H., S. Mazurek, B. Lener, E. Hutter, E. Eigenbrodt, W. Zwerschke, and P. Jansen-Durr. 2008. Premature senescence of human endothelial cells induced by inhibition of glutaminase. Biogerontology 9: 247-259.

185. Eelen, G., P.D. Zeeuw, L. Treps, U. Harjes, B.W. Wong, and P. Carmeliet. 2018. Endothelial cell metabolism. Physiological Reviews 98: 3-58.

186. Schoors, S., U. Bruning, R. Missiaen, K.C. Queiroz, G. Borgers, I. Elia, A. Zecchin, A.R. Cantelmo, S. Christen, J. Goveia, W. Heggermont, L. Godde, S. Vinckier, P.P. Van Veldhoven, G. Eelen, L. Schoonjans, H. Gerhardt, M. Dewerchin, M. Baes, K. De Bock, B. Ghesquiere, S.Y. Lunt, S.M. Fendt, and P. Carmeliet. 2015. Fatty acid carbon is essential for dNTP synthesis in endothelial cells. Nature 520: 192-197.

187. Wong, B.W., E. Marsch, L. Treps, M. Baes, and P. Carmeliet. 2017. Endothelial cell metabolism in health and disease: impact of hypoxia. The EMBO Journal. 36(15): 2187-2203.

188. Karlsson, S., V. Pettila, J. Tenhunen, V. Lund, S. Hovilehto, and E. Ruokonen. 2008. Vascular endothelial growth factor in severe sepsis and septic shock. Anesthesia and Analgesia 106: 1820-1826.

189. Smadja, D.M., D. Borgel, J.L. Diehl, and P. Gaussem. 2012. Vascular endothelial growth factor, as compared with placental growth factor, is increased in severe sepsis but not in organ failure. Journal of Thrombosis and Haemostasis 10: 974-976.

190. van der Flier, M., H.J. van Leeuwen, K.P. van Kessel, J.L. Kimpen, A.I. Hoepelman, and S.P. Geelen. 2005. Plasma vascular endothelial growth factor in severe sepsis. Shock (Augusta, Ga.) 23: 35-38.

191. El-Akabawy, H., M.A. Hamela, A. Gaber, and A. Abozekry. 2016. Prognostic value of vascular endothelial growth factor in sepsis syndrome. The Egyptian Journal of Critical Care Medicine 4: 119-126.
192. Diskin, C., and E.M. Palsson-McDermott. 2018. Metabolic modulation in macrophage effector function. Frontiers in Immunology 9: 270.

193. Koppenol, W.H., P.L. Bounds, and C.V. Dang. 2011. Otto Warburg's contributions to current concepts of cancer metabolism. Nature Reviews. Cancer 11: 325-337.

194. Fukuzumi, M., H. Shinomiya, Y. Shimizu, K. Ohishi, and S. Utsumi. 1996. Endotoxin-induced enhancement of glucose influx into murine peritoneal macrophages via GLUT1. Infection and Immunity 64: 108-112.

195. Tur, J., T. Vico, J. Lloberas, A. Zorzano, and A. Celada. 2017. Macrophages and mitochondria: a critical interplay between metabolism, signaling, and the functional activity. Advances in Immunology 133: 1-36.

196. Rodríguez-Prados, J.-C., P.G. Través, J. Cuenca, D. Rico, J. Aragonés, P. Martín-Sanz, M. Cascante, and L. Boscá. 2010. Substrate fate in activated macrophages: a comparison between innate, classic, and alternative activation. The Journal of Immunology 185: 605-614.

197. Theodorakis, E., Diamantaki, E., Tsatsanis, C., Georgopoulos, D., Vaporidi, K., 2015. Macrophage phenotype in sepsis immunosuppression. Critical Care 19, P44-P44.

198. Watanabe, N., Y. Suzuki, S. Inokuchi, and S. Inoue. 2016. Sepsis induces incomplete M2 phenotype polarization in peritoneal exudate cells in mice. Journal of Intensive Care 4: 6.

199. Kumar, V. 2018b. Targeting macrophage immunometabolism: dawn in the darkness of sepsis. International Immunopharmacology 58: 173-185.

200. Hotchkiss, R.S., P.E. Swanson, B.D. Freeman, K.W. Tinsley, J.P. Cobb, G.M. Matuschak, T.G. Buchman, and I.E. Karl. 1999. Apoptotic cell death in patients with sepsis, shock, and multiple organ dysfunction. Critical Care Medicine 27: 1230-1251.

201. Hotchkiss, R.S., K.W. Tinsley, P.E. Swanson, R.E. Schmieg Jr., J.J. Hui, K.C. Chang, D.F. Osborne, B.D. Freeman, J.P. Cobb, T.G. Buchman, and I.E. Karl. 2001. Sepsis-induced apoptosis causes progressive profound depletion of $\mathrm{B}$ and $\mathrm{CD} 4+\mathrm{T}$ lymphocytes in humans. Journal of immunology (Baltimore, Md. : 1950) 166: 6952-6963.

202. Inoue, S., K. Suzuki-Utsunomiya, Y. Okada, T. Taira, Y. Iida, N. Miura, T. Tsuji, T. Yamagiwa, S. Morita, T. Chiba, T. Sato, and S. Inokuchi. 2013. Reduction of immunocompetent $\mathrm{T}$ cells followed by prolonged lymphopenia in severe sepsis in the elderly. Critical Care Medicine 41: 810-819.

203. Wang, S.D., K.J. Huang, Y.S. Lin, and H.Y. Lei. 1994. Sepsisinduced apoptosis of the thymocytes in mice. Journal of immunology (Baltimore, Md. : 1950) 152: 5014-5021.

204. Chapman, N.M., S. Shrestha, and H. Chi. 2017. Metabolism in immune cell differentiation and function. Advances in Experimental Medicine and Biology 1011: 1-85.

205. MacIver, N.J., R.D. Michalek, and J.C. Rathmell. 2013. Metabolic regulation of T lymphocytes. Annual Review of Immunology 31: 259-283.

206. Venet, F., and G. Monneret. 2018. Advances in the understanding and treatment of sepsis-induced immunosuppression. Nature Reviews. Nephrology 14: 121-137.

207. Andreu-Ballester, J.C., C. Cuellar, C. Garcia-Ballesteros, J. PerezGriera, V. Amigo, A. Peiro-Gomez, C. Penarroja-Otero, F. Ballester, J. Mayans, and C. Tormo-Calandin. 2014. Deficit of interleukin 7 in septic patients. International Immunopharmacology 23: 73-76.

208. Bauer, M., E.J. Giamarellos-Bourboulis, A. Kortgen, E. Moller, K. Felsmann, J.M. Cavaillon, O. Guntinas-Lichius, O. Rutschmann, A. Ruryk, M. Kohl, B. Wlotzka, S. Russwurm, J.C. Marshall, and K. Reinhart. 2016. A transcriptomic biomarker to quantify 
systemic inflammation in sepsis-a prospective multicenter phase II diagnostic study. EBioMedicine 6: 114-125.

209. Wofford, J.A., H.L. Wieman, S.R. Jacobs, Y. Zhao, and J.C. Rathmell. 2008. IL-7 promotes Glut1 trafficking and glucose uptake via STAT5-mediated activation of Akt to support T-cell survival. Blood 111: 2101-2111.

210. Beier, U.H., A. Angelin, T. Akimova, L. Wang, Y. Liu, H. Xiao, M.A. Koike, S.A. Hancock, T.R. Bhatti, R. Han, J. Jiao, S.C. Veasey, C.A. Sims, J.A. Baur, D.C. Wallace, and W.W. Hancock. 2015. Essential role of mitochondrial energy metabolism in Foxp3(+) T-regulatory cell function and allograft survival. FASEB journal : official publication of the Federation of American Societies for Experimental Biology 29: 2315-2326.

211. Michalek, R.D., V.A. Gerriets, S.R. Jacobs, A.N. Macintyre, N.J. MacIver, E.F. Mason, S.A. Sullivan, A.G. Nichols, and J.C. Rathmell. 2011. Cutting edge: distinct glycolytic and lipid oxidative metabolic programs are essential for effector and regulatory CD4+ T cell subsets. Journal of immunology (Baltimore, Md. : 1950) 186: 3299-3303.

212. Newton, R., B. Priyadharshini, and L.A. Turka. 2016. Immunometabolism of regulatory T cells. Nature Immunology 17: 618-625.

213. Zeng, H., K. Yang, C. Cloer, G. Neale, P. Vogel, and H. Chi. 2013. mTORC1 couples immune signals and metabolic programming to establish T(reg)-cell function. Nature 499: 485-490.

214. Kumar, V. 2018a. T cells and their immunometabolism: a novel way to understanding sepsis immunopathogenesis and future therapeutics. European Journal of Cell Biology.

215. Nalos, M., G. Parnell, R. Robergs, D. Booth, A.S. McLean, and B.M. Tang. 2016. Transcriptional reprogramming of metabolic pathways in critically ill patients. Intensive care medicine experimental 4: 21 .

216. Dugnani, E., V. Pasquale, C. Bordignon, A. Canu, L. Piemonti, and P. Monti. 2017. Integrating T cell metabolism in cancer immunotherapy. Cancer Letters 411: 12-18.

217. Mockler, M.B., M.J. Conroy, and J. Lysaght. 2014. Targeting T cell immunometabolism for cancer immunotherapy; understanding the impact of the tumor microenvironment. Frontiers in Oncology 4: 107.

218. Hotchkiss, R.S., and L.L. Moldawer. 2014. Parallels between cancer and infectious disease. The New England Journal of Medicine 371: $380-383$.

219. Hotchkiss, R.S., Moldawer, L.L., Opal, S.M., Reinhart, K., Turnbull, I.R., Vincent, J.L., 2016. Sepsis and septic shock. Nature reviews. Disease primers 2, 16045.

220. Zhang, Z., Deng, W., Kang, R., Xie, M., Billiar, T., Wang, H., Cao, L., Tang, D., 2016. Plumbagin protects mice from lethal sepsis by modulating immunometabolism upstream of PKM2. Molecular medicine (Cambridge, Mass.).

221. O'Neill, L.A., and D.G. Hardie. 2013. Metabolism of inflammation limited by AMPK and pseudo-starvation. Nature 493: 346-355.

222. Sag, D., D. Carling, R.D. Stout, and J. Suttles. 2008. Adenosine 5'monophosphate-activated protein kinase promotes macrophage polarization to an anti-inflammatory functional phenotype. Journal of immunology (Baltimore, Md. : 1950) 181: 8633-8641.

223. Zhu, Y.P., J.R. Brown, D. Sag, L. Zhang, and J. Suttles. 2015. Adenosine 5'-monophosphate-activated protein kinase regulates IL-10mediated anti-inflammatory signaling pathways in macrophages. Journal of immunology (Baltimore, Md. : 1950) 194: 584-594.

224. Escobar, D.A., A.M. Botero-Quintero, B.C. Kautza, J. Luciano, P. Loughran, S. Darwiche, M.R. Rosengart, B.S. Zuckerbraun, and H. Gomez. 2015. AMPK activation protects against sepsis-induced organ injury and inflammation. The Journal of Surgical Research 194: 262-272.

225. Li, Y., N. Nourbakhsh, E. Hall, M. Hepokoski, H. Pham, J. Thomas, and P. Singh. 2016. Protective role of AMPK in sepsis associated AKI. The FASEB Journal 30: 1217.1218.

226. Castanares-Zapatero, D., M. Overtus, D. Communi, M. Horckmans, L. Bertrand, C. Oury, C. Lecut, P. Laterre, S. De man, C. Sommereyns, S. Horman, and C. Beauloye. 2012. AMP-activated protein kinase controls liposaccharide-induced hyperpermeability. Critical Care 16: P17.

227. Huang, J., K. Liu, S. Zhu, M. Xie, R. Kang, L. Cao, and D. Tang. 2017. AMPK regulates immunometabolism in sepsis. Brain, Behavior, and Immunity.

228. Taylor, C.T., and S.P. Colgan. 2017. Regulation of immunity and inflammation by hypoxia in immunological niches. Nature Reviews. Immunology 17: 774-785.

229. Liu, Z., N. Bone, S. Jiang, D.W. Park, J.M. Tadie, J. Deshane, C.A Rodriguez, J.F. Pittet, E. Abraham, and J.W. Zmijewski. 2015. AMP-activated protein kinase and glycogen synthase kinase 3 beta modulate the severity of sepsis-induced lung injury. Molecular medicine 21(1): 937-950.

230. Cheng, S.C., B.P. Scicluna, R.J. Arts, M.S. Gresnigt, E. Lachmandas, E.J. Giamarellos-Bourboulis, M. Kox, G.R. Manjeri, J.A. Wagenaars, O.L. Cremer, J. Leentjens, A.J. van der Meer, F.L. van de Veerdonk, M.J. Bonten, M.J. Schultz, P.H. Willems, P. Pickkers, L.A. Joosten, T. van der Poll, and M.G. Netea. 2016. Broad defects in the energy metabolism of leukocytes underlie immunoparalysis in sepsis. Nature Immunology 17: 406-413.

231. Jha, A.K., S.C. Huang, A. Sergushichev, V. Lampropoulou, Y. Ivanova, E. Loginicheva, K. Chmielewski, K.M. Stewart, J. Ashall, B. Everts, E.J. Pearce, E.M. Driggers, and M.N. Artyomov. 2015. Network integration of parallel metabolic and transcriptional data reveals metabolic modules that regulate macrophage polarization. Immunity 42: 419-430.

232. Van den Bossche, J., L.A. O'Neill, and D. Menon. 2017. Macrophage immunometabolism: where are we (going)? Trends in Immunology 38: 395-406.

233. Mills, E.L., B. Kelly, A. Logan, A.S.H. Costa, M. Varma, C.E. Bryant, P. Tourlomousis, J.H.M. Däbritz, E. Gottlieb, I. Latorre, S.C. Corr, G. McManus, D. Ryan, H.T. Jacobs, M. Szibor, R.J. Xavier, T. Braun, C. Frezza, M.P. Murphy, and L.A. O’Neill. 2016. Succinate dehydrogenase supports metabolic repurposing of mitochondria to drive inflammatory macrophages. Cell 167: 457470.e413.

234. Patil, N.K., J.K. Bohannon, and E.R. Sherwood. 2016. Immunotherapy: a promising approach to reverse sepsis-induced immunosuppression. Pharmacological Research 111: 688-702.

235. Shindo, Y., A.G. Fuchs, C.G. Davis, T. Eitas, J. Unsinger, C.D. Burnham, J.M. Green, M. Morre, G.V. Bochicchio, and R.S. Hotchkiss. 2017. Interleukin 7 immunotherapy improves host immunity and survival in a two-hit model of Pseudomonas aeruginosa pneumonia. Journal of Leukocyte Biology 101: 543-554.

236. Venet, F., Demaret, J., Blaise, B.J., Rouget, C., Girardot, T., Idealisoa, E., Rimmele, T., Mallet, F., Lepape, A., Textoris, J., Monneret, G., 2017. IL-7 restores T lymphocyte immunometabolic failure in septic shock patients through mTOR activation. Journal of immunology (Baltimore, Md. : 1950) 199, 1606-1615.

237. Venet, F., Monneret, G., 2017. Advances in the understanding and treatment of sepsis-induced immunosuppression. Nature reviews. Nephrology.

238. Venet, F., T. Rimmele, and G. Monneret. 2018. Management of sepsisinduced immunosuppression. Critical Care Clinics 34: 97-106. 
239. Francois, B., Jeannet, R., Daix, T., Walton, A.H., Shotwell, M.S., Unsinger, J., Monneret, G., Rimmele, T., Blood, T., Morre, M., Gregoire, A., Mayo, G.A., Blood, J., Durum, S.K., Sherwood, E.R., Hotchkiss, R.S., 2018. Interleukin-7 restores lymphocytes in septic shock: the IRIS-7 randomized clinical trial. JCI insight 3.

240. Angelin, A., Gil-de-Gomez, L., Dahiya, S., Jiao, J., Guo, L., Levine, M.H., Wang, Z., Quinn, W.J., 3rd, Kopinski, P.K., Wang, L., Akimova, T., Liu, Y., Bhatti, T.R., Han, R., Laskin, B.L., Baur, J.A., Blair, I.A., Wallace, D.C., Hancock, W.W., Beier, U.H., 2017. Foxp3 reprograms T cell metabolism to function in low-glucose, high-lactate environments. Cell metabolism 25, 1282-1293.e1287.

241. Grzes, K.M., C.S. Field, and E.J. Pearce. 2017. Treg cells survive and thrive in inhospitable environments. Cell Metabolism 25: 1213-1215.

242. Cao, C., T. Ma, Y.F. Chai, and S.T. Shou. 2015. The role of regulatory $\mathrm{T}$ cells in immune dysfunction during sepsis. World Journal of Emergency Medicine 6: 5-9.

243. Jiang, L.-N., Y.-M. Yao, and Z.-Y. Sheng. 2012. The role of regulatory $\mathrm{T}$ cells in the pathogenesis of sepsis and its clinical implication. Journal of Interferon \& Cytokine Research 32: 341349.

244. Mannick, J.B., M. Morris, H.-U.P. Hockey, G. Roma, M. Beibel, K. Kulmatycki, M. Watkins, T. Shavlakadze, W. Zhou, D. Quinn, D.J. Glass, and L.B. Klickstein. 2018. TORC1 inhibition enhances immune function and reduces infections in the elderly. Science Translational Medicine 10

245. Cantey, J.B., and S.D. Baird. 2017. Ending the culture of culturenegative sepsis in the neonatal ICU. Pediatrics 140.
246. Martín, S., A. Pérez, and C. Aldecoa. 2017. Sepsis and immunosenescence in the elderly patient: a review. Frontiers in Medicine 4: 20.

247. Mayr, F.B., S. Yende, W.T. Linde-Zwirble, O.M. Peck-Palmer, A.E. Barnato, L.A. Weissfeld, and D.C. Angus. 2010. Infection rate and acute organ dysfunction risk as explanations for racial differences in severe sepsis. Jama 303: 2495-2503.

248. Rowe, T.A., and J.M. McKoy. 2017. Sepsis in older adults. Infectious Disease Clinics of North America 31: 731-742.

249. Vardi, M., N.O. Ghanem-Zoubi, H. Bitterman, N. Abo-Helo, V. Yurin, G. Weber, and A. Laor. 2013. Sepsis in nonagenarians admitted to internal medicine departments: a comparative study of outcomes. QJM : Monthly Journal of the Association of Physicians 106: 261-266.

250. Prescott, H.C., and D.C. Angus. 2018. Enhancing recovery from sepsis: a review. Jama 319: 62-75.

251. Allahyari, H., S. Heidari, M. Ghamgosha, P. Saffarian, and J. Amani. 2017. Immunotoxin: a new tool for cancer therapy. Tumor Biology 39: 1010428317692226.

252. Fuchs, H., A. Weng, and R. Gilabert-Oriol. 2016. Augmenting the efficacy of immunotoxins and other targeted protein toxins by endosomal escape enhancers. Toxins 8: 200.

253. Markwart, R., S.A. Condotta, R.P. Requardt, F. Borken, K. Schubert, C. Weigel, M. Bauer, T.S. Griffith, M. Forster, F.M. Brunkhorst, V.P. Badovinac, and I. Rubio. 2014. Immunosuppression after sepsis: systemic inflammation and sepsis induce a loss of naive T-cells but no enduring cell-autonomous defects in T-cell function. PLoS One 9: e115094. 